\title{
Employment subsidies and substitutable skills: An equilibrium matching approach
}

\author{
Gabriele Cardullo* \\ and \\ Bruno Van der Linden**
}

April 13, 2007

Detailed version with appendixes. Forthcoming in Applied Economics Quarterly

\begin{abstract}
The search-matching model is well suited for an equilibrium evaluation of labor market policies. When those policies are targeted on some groups, the usual juxtaposition of labor markets is however a shortcoming. There is a need for a setting where workers' productivity depends on employment levels in all markets. This paper provides such a theoretical setting. We first develop a streamlined model and then show that it can be extended to deal with interactions among various labor market and fiscal policies. Simulation results focus on the effects of employment subsidies and in-work benefits and on their interactions with the profile of unemployment benefits and with active labor market programs.
\end{abstract}

JEL Classification: E24, J68, H2

Keywords: search-matching equilibrium; reductions of social security contributions; labor market programs.

\section{Introduction}

To boost employment among the relatively low-paid, several countries have introduced employment subsidies, in-work benefits or cut in payroll taxes. In frictional labor

\footnotetext{
${ }^{*}$ Institut de Recherches économiques et sociales, Département des Sciences Economiques, Université Catholique de Louvain, Belgium. Gabriele Cardullo gratefully acknowledges a grant of the Belgian National Bank.

** Fonds National de la Recherche Scientifique, Institut de Recherches économiques et sociales, Département des Sciences Economiques, Université Catholique de Louvain, Belgium and IZA, Bonn. This research has been funded by the Belgian Federal Science Policy Office in it's program "Actual problems concerning social cohesion" (2001-2005) and by the Belgian Program on Interuniversity Poles of Attraction (P6/07 Economic Policy and Finance in the Global Economy: Equilibrium Analysis and Social Evaluation) initiated by the Belgian State, Prime Minister's Office, Science Policy Programming. The scientific responsibility is assumed by the authors. We thank Bart Cockx, David de la Croix, Etienne Lehmann, Frank Portier, Fabien Postel-Vinay, Henri Sneessens, an anonymous referee and the participants to the IZA workshop "Structural econometric analysis of labor market policy" for useful discussions and comments. Any remaining errors are our own.
} 
markets, these fiscal instruments change the quasi-rents that accrue to employers and workers who have matched. This induces various effects on firms' and workers' decisions. Developing a comprehensive view of these effects is essential to evaluate whether these fiscal instruments can alleviate the unemployment problem. The equilibrium matching theory is admittedly a powerful setting for such an evaluation. Davidson and Woodbury (1993) develop a matching model with different types of workers where the total number of jobs is given. At the other extreme, in Mortensen and Pissarides (2003), firms supply their optimal amount of a final good facing a infinitely elastic demand. Mortensen and Pissarides (2003) are conscious that the second assumption, henceforth the "M-P assumption", remains quite restrictive. They write: "One way to introduce a middle ground would be to assume that worker productivity depends on employment levels" (p. 72). The present paper develops this idea.

This paper makes a second contribution. Fiscal reforms do not take place in isolation. They interact with other existing policies. Some papers have looked at interactions with employment protection (see e.g. Mortensen and Pissarides 2003). Our paper looks at the interplay between the profile of unemployment insurance (respectively, short-duration active programs) and fiscal reforms targeted on low-skilled workers.

We consider an economy with a final consumption good produced with two substitutable intermediate goods under constant returns to scale. ${ }^{1}$ Each of them is produced with a single input, namely labor of a given skill. The marginal product of labor is constant. An additional vacancy accessible to one type of worker increases employment and the quantity of the corresponding intermediate good. This decreases its productivity in the production of the final good and raises the productivity of the other intermediate good. These changes in productivity modify the marginal value of labor and hence the quasi-rents that accrue to employers and workers in all the economy. The decision to open new vacancies and the effort to search for a job are therefore affected, too. These new interactions complement the standard matching externalities ("caused by the congestion that searching firms and workers cause for each other during trade", Pissarides 2000, p.8). We show that the steady-state equilibrium of this economy is unique.

This framework is then further generalized to deal with some labor market policies ('LMPs') extensively used in OECD economies. Our aim is to show how a generalization of the M-P setting can be used to look at the interactions between employment subsidies and other LMPs. First, we introduce a two-tier benefit system (a stylized representation of many unemployment schemes). As many authors (see e.g. Fredriksson and Holmlund 2001, or Albrecht and Vroman 2005), we assume that the fall from the 'high' to the 'low' benefit occurs at a Poisson rate. Compared to a flat rate, time-varying

\footnotetext{
${ }^{1}$ Acemoglu (2001), Joseph, Pierrard and Sneessens (2004) and Pierrard (2005) use a similar setting.
} 
unemployment benefits have different effects on job-search and on the wage bargain (Cahuc and Lehmann 2000, Fredriksson and Holmlund 2001, and Coles and Masters 2006). Second, we add short-duration active labor market programs (counseling, job clubs, among others) that enhance the matching effectiveness of the participants. They influence job-search intensity (see Van der Linden 2005) and wage formation (see Holmlund and Lindén 1993). However, by assumption, this kind of active program does not modify workers' productivity. More generally, the model takes the distribution of skills as given. On the role of wage subsidies on human capital, see Heckman, Lochner and Cossa (2003) and Blundell, Costa-Dias and Meghir (2003).

A natural question is to what extent these extensions to the Mortensen and Pissarides model lead to different properties. To answer this question, as M-P, we introduce a tax-subsidy schedule $a+\tau w$, where $w$ is the net wage rate and $\tau$ is a positive proportional tax rate. If $a$ is negative, it can be interpreted as a lump-sum employment subsidy (the interpretation retained below), in-work benefit or cut in payroll taxes. Trough bargaining, the employment subsidy is partly used to raise net wages and partly to raise employment. In the case of a lump-sum employment subsidy targeted on the low-skilled workers, we show that the M-P model overestimates (respectively, underestimates) its effect on low-skilled (respectively, high-skilled) employment.

We develop a simulation exercise to provide order of magnitudes of the various effects. Contrary to what is often done, we do not contrast highly stylized European and Nord-American economies. Instead, we calibrate and then simulate the model for a specific country plagued with a large low-skill problem and an important tax wedge (Belgium). ${ }^{2}$ We consider an employment subsidy on the low-skilled amounting to an ex ante reduction of $12 \%$ of their wage cost. With an elasticity of substitution between skilled and unskilled labor close to 1 , the M-P model overestimates the impact on lowskilled employment by $5 \%$ and underestimates the impact on high-skilled employment by $0.7 \%$. The differences are more important in terms of job-search effort and utility levels. Altogether, this leads to very different normative conclusions. The optimal low-skilled employment subsidy (i.e., the one maximizing net output) is $63 \%$ larger in the M-P model.

Economists are nowadays more and more conscious that labor market reforms should be comprehensive. Theoretical analyses of complementarities can be found in Coe and Snower (1997), Orszag and Snower (1998), Chapter 4 of OECD (2003)

\footnotetext{
${ }^{2}$ Compared to individuals holding a higher education degree, the unemployment rate of those with at most a lower-secondary education level is about three times higher. As other countries of Western Europe, Belgium extensively uses reductions of employers' social security contributions targeted on low-skilled workers. Reductions of social security contributions amounted to $1.2 \%$ of GDP in 2004. In addition, a tax reform has been introduced in Belgium in 2001. Despite a small individualized income tax credit at the bottom of the income distribution, the effects of the reform in terms of increase in disposable income appear to be strongest for the middle to upper class..
} 
and Boone and van Ours (2004). Dealing with imperfectly substitutable skills and endogenous search allows to extend this literature. Empirical analyses, such as Nickell and Layard (1999) and Belot and van Ours (2004), conclude that particular combinations of labor market institutions and policies can be responsible of good or bad performances on the labor market. These analyses are however constrained by the availability of data. Some features such as the profile of unemployment benefits can at best be proxied by some aggregate indicators. Simulations of an equilibrium matching framework seem to be preferable. To the best of our knowledge, the literature has paid scant attention to the complementarities between employment subsidies on the one hand and the time-profile of unemployment benefits and active labor market policies on the other hand. Our simulations show that the efficiency of employment subsidies can be reinforced by reforms to active and passive labor market policies.

This paper is organized as follows. Section 2 introduces the model. A streamlined version is first presented and then generalized to deal with active and passive programs. Section 3 explains how the model has been calibrated and validated. Section 4 presents simulation results and Section 5 concludes the paper.

\section{The framework}

\subsection{A model where worker productivity depends on employment levels}

Consider a continuous-time model with a continuum of infinitely-lived and riskneutral workers who have perfect foresight. Each firm is made of a single (filled or vacant) job. There are frictions on the labor market. Other markets are instead frictionless (perfect competition prevails). Assume two skill groups (high-skilled indexed by $h$ and low-skilled indexed by $l$ ) and skill-specific technologies. Let $y_{n}$ denote the fixed marginal products of labor $\left(y_{l}<y_{h}\right)$ and $E_{n}$ the employment levels $(n \in\{l, h\})$. Total output is a convex combination of $E_{l} y_{l}$ and $E_{h} y_{h}$. The interpretation is the following. A single final good (the numeraire) is produced with two intermediate goods. Let $Q_{l}$ (respectively, $Q_{h}$ ) denote the amount of the low-skilled intermediate good (respectively, the high-skilled intermediate good). Keeping $y_{n}$ constant, we have $Q_{n}=E_{n} y_{n}$. The final good production function is homogeneous of degree one. Total output is now given by $F\left(Q_{l}, Q_{h}\right)$, with :

$$
\frac{\partial F}{\partial Q_{n}}>0, \lim _{Q_{n} \rightarrow 0} \frac{\partial F}{\partial Q_{n}}=+\infty, \lim _{Q_{n} \rightarrow+\infty} \frac{\partial F}{\partial Q_{n}}=0 \text { and } \frac{\partial^{2} F}{\partial Q_{n}{ }^{2}}<0, n \in\{h, l\} .
$$

The two inputs are p-substitutes $\left(0<\frac{\partial^{2} F}{\partial Q_{l} \partial Q_{h}}<+\infty\right)$. Compared to the M-P assumption, there are two differences. First, the elasticity of substitution between the two skills can take any positive value. The higher the elasticity of substitution, the closer 
we are to the M-P assumption. ${ }^{3}$ Second, the marginal value of labor now varies with the number of workers in both sectors. Let $p_{n}$ denote the real price of the intermediate good $n$. Profit maximization in the final good firm implies that

$$
p_{n}=\frac{\partial F\left(E_{l} y_{l}, E_{h} y_{h}\right)}{\partial E_{n} y_{n}} .
$$

The marginal value product of labor depends negatively on the number of workers employed in the sector (since $\left.\partial p_{n} / \partial E_{n}<0\right)^{4}$ and positively on the number of workers employed in the other sector $\left(\partial p_{n} / \partial E_{m}>0, n \neq m\right)$.

The other assumptions are standard. Workers are able to direct their search. The flow of hires, $M_{n}$ is a function of the number of vacancies, $V_{n}$ and the number of jobseekers measured in efficiency units, $s_{n} U_{n}$, where $s_{n}$ designates the job-search effort of the $U_{n}$ unemployed. $L_{n}$ denotes the size of the labor force. The matching function is written $M_{n}=m\left(s_{n} U_{n}, V_{n}\right)$. The function $m(.,$.$) is assumed to be increasing, concave$ and homogeneous of degree 1 . Tightness is measured in efficiency units, namely $\theta_{n} \equiv$ $V_{n} /\left(s_{n} U_{n}\right)$ or equivalently, after division by the exogenous and constant labor force $L_{n}$, $\theta_{n} \equiv v_{n} /\left(s_{n} u_{n}\right)$. The rate at which vacant jobs become filled is $q\left(\theta_{n}\right) \equiv M_{n} / V_{n}, q^{\prime}\left(\theta_{n}\right)<$ 0 . A job-seeker moves into employment according to a Poisson process with rate $s_{n} \alpha\left(\theta_{n}\right) \equiv s_{n} \theta_{n} q\left(\theta_{n}\right)$, with $\alpha^{\prime}\left(\theta_{n}\right)>0$. Moreover, it is assumed that $\lim _{\theta_{n} \rightarrow 0} q\left(\theta_{n}\right)=+\infty$ and $\lim _{\theta_{n} \rightarrow 0} \alpha\left(\theta_{n}\right)=0$.

The model is developed in steady state and in continuous time. The equality between separations (occurring at an exogenous rate $\phi_{n}$ ) and entries lead to an increasing relationship between employment on the one hand, search and tightness on the other

$$
E_{n}=\mathbb{E}\left(\theta_{n}, s_{n}\right) \equiv \frac{s_{n} \alpha\left(\theta_{n}\right)}{\phi_{n}+s_{n} \alpha\left(\theta_{n}\right)} L_{n}
$$

Substituting this expression in (2) yields $p_{n}=p_{n}\left(\theta_{l}, s_{l}, \theta_{h}, s_{h}\right)$. Individuals have no access to capital markets. Let $r$ be the discount rate common to all agents. For a worker endowed with skill $n$, the discounted present value in employment, $V_{E, n}$ verifies:

$$
r V_{E, n}=w_{n}+\phi_{n}\left(V_{U, n}-V_{E, n}\right)
$$

where $w_{n}$ is the net wage in the $n$th intermediate sector (working time is normalized to 1) and $V_{U, n}$ represents the discounted expected lifetime income of an unemployed.

\footnotetext{
${ }^{3}$ The elasticity of substitution between skilled and unskilled labor lies between 1 and 2 (Cahuc and Zylberberg 2004, p. 211).

${ }^{4}$ A similar property could also be achieved with "large" firms and diminishing returns to labor. However, we here avoid the complex intra-firm bargaining issues (see Stole and Zwiebel 1996, and Cahuc and Wasmer 2001).
} 
We assume that the instantaneous utility in unemployment is equal to the level of unemployment benefits (proportional to the net wages) net of the cost of job-search $d\left(s_{n}\right)$ (with $d(0)=0, d^{\prime}>0$ and $\left.d^{\prime \prime}>0\right)$. Denoting the replacement ratio by $\rho_{n}, V_{U, n}$ verifies the following Bellman equation:

$$
r V_{U, n}=\max _{s_{n}}\left\{\rho_{n} w_{n}-d\left(s_{n}\right)+s_{n} \alpha\left(\theta_{n}\right)\left(V_{E, n}-V_{U, n}\right)\right\} .
$$

At each point in time, the unemployed chooses the best level of job-search taking tightness and the net intertemporal gain as given. The first-order (and sufficient) condition balances the marginal cost of search and the corresponding marginal gain:

$$
d^{\prime}\left(s_{n}\right)=\alpha\left(\theta_{n}\right)\left(V_{E, n}-V_{U, n}\right) .
$$

Let $\Pi_{E, n}$ denote the firm's discounted expected return from an occupied job if the firm produces the $n$th intermediate good (and recruits workers endowed with skill $n$ ). For simplicity, taxation is linear. Let $a_{n}+\tau_{n} w_{n}$ be the amount of taxes paid if the net wage is $w_{n}\left(\tau_{n} \geq 0\right)$. According to its sign, $a_{n}$ is an employer tax or subsidy. It does not matter which side of the market pays or receives $a_{n}$. So, the latter can also be interpreted as a lump-sum in-work tax or subsidy. Each filled vacancy yields $y_{n}$ units of output times the price $p_{n}$ of the intermediate good. The discounted expected return of a vacant job in sector $n$ is denoted by $\Pi_{V, n}$. Let $k_{n}$ be the flow cost of posting a vacancy. The discounted expected returns satisfy the following conditions:

$$
\begin{aligned}
r \Pi_{E, n} & =p_{n} y_{n}-a_{n}-\left(1+\tau_{n}\right) w_{n}+\phi_{n}\left(\Pi_{V, n}-\Pi_{E, n}\right), \\
r \Pi_{V, n} & =-k_{n}+q\left(\theta_{n}\right)\left(\Pi_{E, n}-\Pi_{V, n}\right) .
\end{aligned}
$$

There is free entry of vacancies. In equilibrium, $\Pi_{V, n}$ then equals 0 in each sector. From (7) and (8), the demand side of the market can be summarized by the following "vacancy-supply curve" relating the wage and tightness on the labor market for skill $n$ :

$$
w_{n}=V S_{n}\left(\theta_{l}, s_{l}, \theta_{h}, s_{h}\right) \equiv \frac{p_{n}\left(\theta_{l}, s_{l}, \theta_{h}, s_{h}\right) y_{n}-a_{n}-\left(r+\phi_{n}\right)\left(k_{n} / q\left(\theta_{n}\right)\right)}{1+\tau_{n}},
$$

with $\partial V S_{n} / \partial \theta_{n}<0$. Higher tax parameters have a negative effect on the 'feasible' wage $w_{n} \forall\left(\theta_{l}, s_{l}, \theta_{h}, s_{h}\right)$.

When a worker and an employer form a match, the surplus $V_{E, n}-V_{U, n}+\Pi_{E, n}$ is shared through bargaining. ${ }^{5}$ Under Nash bargaining, if $\beta_{n}$ denotes the exogenous

\footnotetext{
${ }^{5}$ In some countries, like France, the wage of the low-skilled is not bargained over but equal to the legal minimum wage. The latter is periodically adjusted upwards to keep relative wages approximately constant. We have verified that the qualitative properties of the employment subsidy remain when $w_{h}$ is negotiated and $w_{l}=a w_{h}$, where $a$ is an exogenous parameter $(0<a<1)$.
} 
bargaining power of the type- $n$ worker $\left(0<\beta_{n}<1\right)$, the solution to the game can be written as

$$
\left(1-\beta_{n}\right)\left(1+\tau_{n}\right)\left(V_{E, n}-V_{U, n}\right)=\beta_{n} \Pi_{E, n} .
$$

This property, the Bellman equations (4) and (5) and the free-entry condition $\left(\Pi_{E, n}=\right.$ $k / q\left(\theta_{n}\right)$ ) lead then to the following "wage-setting curve":

$$
w_{n}=W S_{n}\left(\theta_{n}, s_{n}\right) \equiv \frac{1}{1-\rho_{n}}\left[\frac{\beta_{n}}{1-\beta_{n}} \frac{k_{n}}{1+\tau_{n}}\left(s_{n} \theta_{n}+\frac{r+\phi_{n}}{q\left(\theta_{n}\right)}\right)-d\left(s_{n}\right)\right],
$$

with $\partial W S_{n} / \partial \theta_{n}>0$. A rise in $\tau_{n}$ has a negative effect on the bargained wage $\forall\left(\theta_{n}, s_{n}\right)$. However, the effect is less than proportional since the instantaneous income in unemployment contains an untaxed component $-d\left(s_{n}\right)$.

Under free entry and taking (10) into account, the optimality condition (6) becomes:

$$
d^{\prime}\left(s_{n}\right)=\frac{\beta_{n}}{1-\beta_{n}} \frac{k_{n}}{1+\tau_{n}} \theta_{n} .
$$

This defines an implicit increasing relationship between $s_{n}$ and $\theta_{n}$. Conditional on tightness, a rise in the tax rate $\tau_{n}$ lowers the equilibrium return of search and hence search effort. From (12), it is obvious that a marginal change in job-search effort does not shift the wage-setting curve.

The relationship $V S_{n}-W S_{n}=0$ can be written as:

$$
\begin{aligned}
\mathbb{G}_{n} \equiv & \left(1-\rho_{n}\right)\left(1-\beta_{n}\right)\left\{p_{n} y_{n}-a_{n}\right\}-\left(1-\left(1-\beta_{n}\right) \rho_{n}\right) \frac{\left(r+\phi_{n}\right) k_{n}}{q\left(\theta_{n}\right)} \\
& -\beta_{n} s_{n} k_{n} \theta_{n}+\left(1-\beta_{n}\right)\left(1+\tau_{n}\right) d\left(s_{n}\right)=0
\end{aligned}
$$

in which $p_{n}=p_{n}\left(\theta_{l}, s_{l}, \theta_{h}, s_{h}\right)$. Taking the implicit relationship (12) between search effort and tightness into account, differentiating $\mathbb{G}_{n}$ yields $\forall n$ :

$$
\begin{aligned}
& \frac{\partial \mathbb{G}_{n}}{\partial \theta_{n}}=A_{n}+B_{n}<0 \\
& \frac{\partial \mathbb{G}_{n}}{\partial \theta_{m}}=C_{n, m}>0
\end{aligned}
$$

in which

$$
\begin{aligned}
A_{n} & =\left(1-\left(1-\beta_{n}\right) \rho_{n}\right) \frac{\left(r+\phi_{n}\right) k_{n}}{q\left(\theta_{n}\right)^{2}} q^{\prime}\left(\theta_{n}\right)-\beta_{n} s_{n} k_{n}<0, \\
B_{n} & =\left(1-\rho_{n}\right)\left(1-\beta_{n}\right) \frac{\partial p_{n}}{\partial y_{n} E_{n}} y_{n}\left[\frac{\partial \mathbb{E}_{n}}{\partial \theta_{n}}+\frac{\partial \mathbb{E}_{n}}{\partial s_{n}} \frac{\partial s_{n}}{\partial \theta_{n}}\right]<0, \\
C_{n, m} & =\left(1-\rho_{n}\right)\left(1-\beta_{n}\right) \frac{\partial p_{n}}{\partial y_{m} E_{m}} y_{m}\left[\frac{\partial \mathbb{E}_{m}}{\partial \theta_{m}}+\frac{\partial \mathbb{E}_{m}}{\partial s_{m}} \frac{\partial s_{m}}{\partial \theta_{m}}\right]>0 .
\end{aligned}
$$




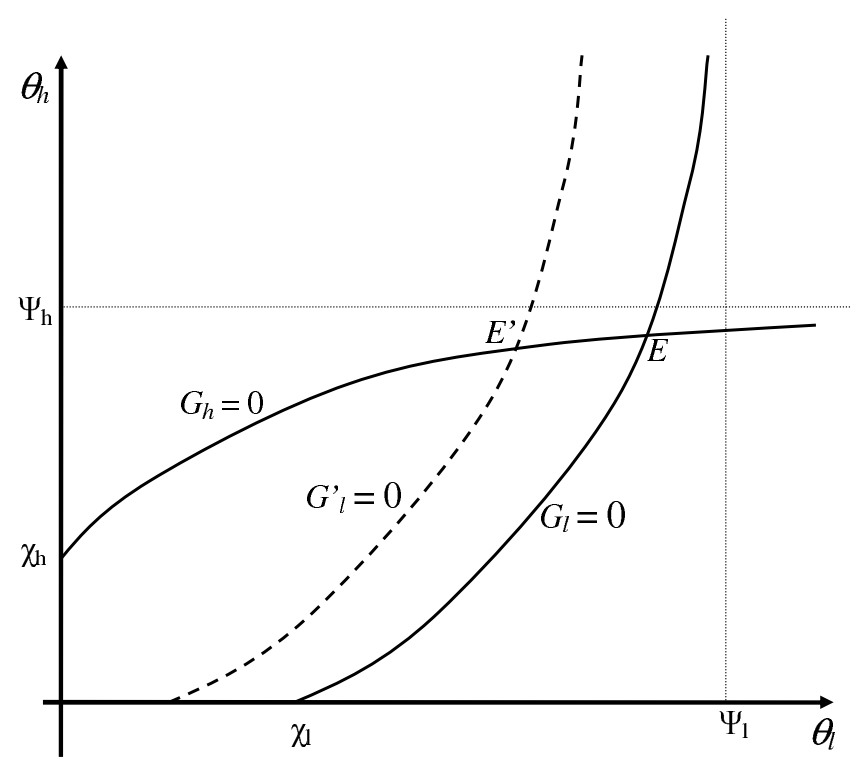

Figure 1: The unique steady-state equilibrium.

In these expressions, $A_{n}<0$ is the effect found in the standard matching model. A higher tightness raises the exit rate out of unemployment (pushing bargained wages upwards) and increases the expected duration needed to fill a vacancy (reducing the wage that firms can afford under free entry). $B_{n}$ is a new negative term that captures the effects of a higher tightness in sector $n$ on employment in this sector and hence on the price of the corresponding intermediate good. ${ }^{6}$ As the labor market becomes more tight, employment increases. In addition, a higher job finding rate raises search effort which in turn raises employment. These combined positive effects on employment lower the marginal product of the corresponding intermediate good in the production of the final good. Hence, the equilibrium price $p_{n}$ shrinks and this depresses the creation of vacancies. Finally, $C_{n, m}$ captures a positive cross effect. Increasing tightness in sector $m$ raises employment in this sector. As the two intermediate goods are substitutes, the marginal product of the other intermediate good increases and this eventually stimulates the opening of vacancies in the other sector $(n)$.

Figure 1 about here

In steady-state, the equilibrium pair(s) $\left(\theta_{l}, \theta_{h}\right)$ verify the system of equations $\mathbb{G}_{l}=$ $\mathbb{G}_{h}=0$. Each of these equalities define an increasing implicit relationship between $\theta_{l}$

${ }^{6}$ The partial derivative of the price $\partial p_{n} / \partial y_{n} E_{n}$ is computed from (2) and is negative. $\partial \mathbb{E}_{n} / \partial \theta_{n}$ and $\partial \mathbb{E}_{n} / \partial s_{n}$ are computed from (3) and are positive. Finally, $\partial s_{n} / \partial \theta_{n}$ is computed from (12) and is positive. 
and $\theta_{h}$. It is therefore far from obvious that an equilibrium exists and is unique. This property is shown in Appendix A. Figure 1 illustrates the equilibrium. Knowing the levels of tightness, the values of employment and net wages follow immediately from (3), (12) and (11).

We now look at the partial ${ }^{7}$ effects of changes in the lump-sum employment tax/subsidy, $a_{n}$, and in the tax rate, $\tau_{n}$. We only consider the case $n=l$ and focus on equilibrium tightness. It should be clear that the comparative static properties are derived for an equilibrium $\left(\theta_{l}, \theta_{h}\right)$ that would be the same under the M-P assumption and in our setting.

Effects of the lump-sum employment tax/subsidy

Consider a marginal change in $a_{l}$. Under the M-P assumption, the real price of the two intermediate goods being constant, the effect on tightness would be:

$$
\begin{aligned}
\frac{d \theta_{l}}{d a_{l}} & =-\left(\frac{d \mathbb{G}_{l}}{d a_{l}}\right) /\left(\frac{d \mathbb{G}_{l}}{d \theta_{l}}\right)=\left(1-\rho_{l}\right)\left(1-\beta_{l}\right) / A_{l}<0 \\
\frac{d \theta_{h}}{d a_{l}} & =0
\end{aligned}
$$

Taking the endogeneity of prices into account, one gets after some manipulation:

$$
\begin{aligned}
\frac{d \theta_{l}}{d a_{l}} & =\mu_{l}\left(1-\rho_{l}\right)\left(1-\beta_{l}\right) / A_{l}<0, \\
\frac{d \theta_{h}}{d a_{l}} & =-\frac{\left(1-\rho_{l}\right)\left(1-\beta_{l}\right) C_{h, l}}{\left(A_{l}+B_{l}\right)\left(A_{h}+B_{h}\right)-C_{l, h} C_{h, l}}<0,
\end{aligned}
$$

where, exploiting Euler's formula for linear homogeneous function, ${ }^{8}$ one has:

$$
\mu_{l}=\frac{A_{l}\left(A_{h}+B_{h}\right)}{\left(A_{l}+B_{l}\right)\left(A_{h}+B_{h}\right)-C_{l, h} C_{h, l}}=\frac{A_{l}\left(A_{h}+B_{h}\right)}{A_{l}\left(A_{h}+B_{h}\right)+B_{l} A_{h}}<1 .
$$

Figure 1 illustrates these effects (see the interrupted line). So, compared to the case where the real prices of the two intermediate goods are taken as constant, $d \theta_{l} / d a_{l}$ is less negative. Two opposite effects are present. First, if the employment tax is augmented in a given sector, say $l$, there is at given prices $\left(p_{l}, p_{h}\right)$ a reduction in tightness and hence in employment in this sector. Less employment implies a rise in the marginal product of workers and this leads to a higher price for the corresponding intermediate good $Q_{l}$.

\footnotetext{
${ }^{7}$ At this stage, the budget of the State is ignored. When the budget of the State is binding, the uniqueness of equilibrium is not always guaranteed (see Rocheteau 1999). Appendix A presents sufficient conditions for a unique equilibrium.

8 Namely, $\frac{\partial^{2} F}{\partial^{2} Q_{n}} \frac{\partial^{2} F}{\partial^{2} Q_{m}}=\left[\frac{\partial^{2} F}{\partial Q_{m} \partial Q_{n}}\right]^{2}$.
} 
More vacancies are therefore posted. This attenuates the initial drop in employment. Second, less employment in sector $l$, where the employment tax is augmented, implies a lower marginal product of the other intermediate good $Q_{h}$. Less vacancies are therefore created in sector $h$. And this in turn depresses job creation in sector $l$. One easily sees that this chain of effects creates a multiplicative effect which tends to amplify the initial decline in tightness $\theta_{l}$. Since $0<\mu_{l}<1$, the first effect dominates.

This discussion implies that an employment subsidy in the low-skill sector will rise its tightness level less than under the M-P assumption. The induced effect of the employment subsidy is moreover positive in the skilled sector (while it is zero under the M-P assumption). The quantitative importance of these differences will be studied in Section 4.

It should also be noticed that contrary to the standard M-P model (in which marginal variations in search effort do not affect tightness in equilibrium), endogeneizing search effort matters here. For, marginal changes in search effort affect the level of employment (see (3)) and hence the prices of the intermediate goods. The equilibrium levels of tightness are therefore eventually modified. Consequently, endogeneizing search effort changes the impacts of the tax parameters $a_{n}$ and $\tau_{n}$ in our model.

Effects of the tax rate

Consider a marginal change in the tax parameter $\tau_{l}$. Totally differentiating $\mathbb{G}_{l}=$ $\mathbb{G}_{h}=0$ with respect to $\theta_{l}, \theta_{h}$ and $\tau_{l}$, it can be verified that the sign of the variation in both $\theta_{l}$ and $\theta_{h}$ is the one of $\partial \mathbb{G}_{l} / \partial \tau_{l}$. From (13), the latter is:

$$
\frac{\partial \mathbb{G}_{l}}{\partial \tau_{l}}=\left(1-\beta_{l}\right)\left[y_{l}\left(1-\rho_{l}\right) \frac{\partial p_{l}}{\partial y_{l} E_{l}} \frac{\partial \mathbb{E}_{l}}{\partial s_{l}} \frac{\partial s_{l}}{\partial \tau_{l}}+d\left(s_{l}\right)\right]>0
$$

in which $\partial s_{l} / \partial \tau_{l}<0$. Two mechanisms are at work. First, rising the tax rate $\tau_{l}$ reduces search effort and hence employment in Sector $l$. This raises the equilibrium price for the intermediate good sold by this sector. So, the first product between brackets in (23) is nonnegative. The second mechanism is not new (see Holmlund 2002). Search activities entail an untaxed cost, namely $d\left(s_{n}\right)$. Therefore, despite constant replacement ratios, bargained wages adjust more than proportionally when the tax rate rises (see (11)). Now, the feasible wage, (9), adjusts proportionally. These adjustments are not compatible in equilibrium. A rise in tightness $\theta_{l}$ is needed to restore equilibrium.

\subsection{Generalizing the model to encompass other LMPs}

Employment subsidies do not take place in isolation. They are typically introduced in labor markets where so-called active and passive LMPs are also present. Building upon Van der Linden (2005), we now show how the framework of the previous subsection can be further extended to evaluate the interactions between these policies in a 
general equilibrium setting. The model will also be generalized to deal with participation decisions and an aggregate budget constraint of the State. Some hypotheses will be chosen with Continental Europe in mind.

In accordance with institutions in many OECD countries, a two-tiered benefit system is assumed to prevail. An insured unemployed whose 'high' benefits have expired enters a state where (s)he indefinitely can benefit from a lower unemployment (assistance) benefit. High benefits expire at an exogenous rate $\pi_{n}>0$. For jobless individuals, three states are identified: Insured unemployment with high benefits $\left(U_{n}\right)$, insured unemployment with low benefits $\left(X_{n}\right)$ and participation $\left(T_{n}\right)$ in a short-duration active labor market policy (ALMP) organized by the Public Employment Services (PES). We have in mind counseling programs, job clubs or very brief training schemes. By assumption, these policies do not change the productivity of the participants. ${ }^{9}$ These upper-case symbols will designate both the states and the number of individuals occupying them in steady state. The corresponding intertemporal discounted values will be denoted by $V_{U, n}, V_{X, n}$ and $V_{T, n}$. Figure 2 displays the various states and the flows in this economy. A growing literature shows that duration dependence is largely spurious in Continental Europe (see van den Berg and van Ours 1999, Machin and Manning 1999, Rosholm 2001, and Dejemeppe 2005). True duration dependence is therefore assumed to be a negligible phenomenon in this economy.

Figure 2 about here

Let $s_{U, n}, s_{X, n}$ and $s_{T, n}$ denote search intensities in the various states. A unique exogenous matching effectiveness parameter $c_{n}$ will be associated to states $U_{n}$ and $X_{n}$. For ALMP participants, this parameter can be different and will be denoted $c_{T, n}$. It is assumed that $c_{T, n}>c_{n}>0 .{ }^{10}$ So, in the matching function $m\left(S_{n}, V_{n}\right)$, $S_{n} \equiv c_{n}\left(s_{U, n} U_{n}+s_{X, n} X_{n}\right)+c_{T, n} s_{T, n} T_{n}$ and tightness is defined as $\theta_{n} \equiv V_{n} / S_{n}$.

The unemployed receive an offer to take part to the ALMP at an exogenous rate $\gamma_{n} \geq 0 .{ }^{11}$ The unemployed have then to decide whether they enter the program

${ }^{9}$ It should be stressed that this chapter does not deal with (long-duration training) schemes that intend to enhance skills (see Albrecht, van den Berg and Vroman 2006, and Boone and van Ours 2004) or to enlarge the set of occupations that are accessible (see Masters 2000).

10 The ALMP can intrinsically improve the effectiveness of search effort. Alternatively, the PES can for instance give priority to participants to ALMP, in particular in the case of a closed treatment of job offers. This refers to the case where the PES select those who are suitable for vacancies in their register.

11 Conditioning the access to an ALMP on the level of unemployment benefits would be considered as discriminatory. So, this possibility is ruled out here. As it is observed in several countries, participation to active programs is a sufficient condition to become eligible to high benefits again. Relaxing this assumption would substantially complicate the mathematical expressions used below and in the appendixes without adding much insight. 
(right away) or not. Two cases will be distinguished. First, this offer is not used to verify the availability of the unemployed. Then, the intertemporal value of those who receive an offer in state $U_{n}$ (resp., $\left.X_{n}\right)$ is $\bar{V}_{U, n}=\max \left(V_{T, n} ; V_{U, n}\right)$ (resp., $\bar{V}_{X, n}=$ $\left.\max \left(V_{T, n} ; V_{X, n}\right)\right)$. Second, this offer is used to monitor the unemployed. Someone in state $U_{n}$ can be sanctioned if (s)he refuses to take part to the program. Let the sanction be an immediate entry in state $X_{n}$. Then, $\bar{V}_{U, n}=\max \left(V_{T, n} ; V_{X, n}\right)$. $\bar{V}_{X, n}$ remains unchanged. Finally, to capture the idea that the ALMP can be unsuccessful, it is assumed that the program fails at an exogenous rate $\lambda_{n} \geq 0$.

In steady state, equalities between entries and exits in each state $\left(U_{n}, X_{n}, \ldots\right)$ determine the level of employment $E_{n}$ for each skill $n$. $E_{n}$ increases $\theta_{n}$ and search effort levels $\mathbb{S}_{n} \equiv\left(s_{U, n}, s_{X, n}, s_{T, n}\right)$ (for details, see Appendix C).

If the wage negotiation took place at the individual level, the (entry) wage would be different according to the state of origin. Having Continental Europe in mind, as Cahuc and Lehmann (2000), we assume instead that the wage in sector $n$ is bargained over by incumbent employees on behalf of all workers of this sector. The fall-back position of these "insiders" is the intertemporal value of an unemployed entering state $U_{n}, V_{U, n}$. Then, the skill-specific wage is unique. The discounted value of holding a job still verifies (4). We keep the hypothesis of constant replacement ratios and assume the following very plausible ranking: $1>\rho_{T, n} \geq \rho_{U, n}>\rho_{X, n}>0$. Let $v_{\iota, n} \equiv$ $\left.\rho_{\iota, n} w_{n}-d\left(s_{\iota, n}\right)\right) \geq 0, \iota \in\{U, X, T\}$. For jobless people endowed with skill $n$, the intertemporal values solve the following equations:

$$
\begin{aligned}
& r V_{U, n}=\max _{s_{U, n}}\left\{v_{U, n}+c_{n} s_{U, n} \alpha\left(\theta_{n}\right)\left(V_{E, n}-V_{U, n}\right)+\gamma_{n}\left(\bar{V}_{U, n}-V_{U, n}\right)+\pi_{n}\left(V_{X, n}-V_{U, n}\right)\right\}, \\
& r V_{X, n}=\max _{s_{X, n}}\left\{v_{X, n}+c_{n} s_{X, n} \alpha\left(\theta_{n}\right)\left(V_{E, n}-V_{X, n}\right)+\gamma_{n}\left(\bar{V}_{X, n}-V_{X, n}\right)\right\}, \\
& r V_{T, n}=\max _{s_{T, n}}\left\{v_{T, n}+c_{T, n} s_{T, n} \alpha\left(\theta_{n}\right)\left(V_{E, n}-V_{T, n}\right)+\lambda_{n}\left(V_{U, n}-V_{T, n}\right)\right\} .
\end{aligned}
$$

Under the assumptions made so far and if $\lambda_{n}>\phi_{n},{ }^{12}$ Appendixes $\mathrm{B}$ and $\mathrm{C}$ show that the intertemporal values can always be ranked $\left(V_{E, n}>V_{T, n}>V_{U, n}>V_{X, n}\right)$. Consequently, all the unemployed choose to take part to the program and $\bar{V}_{U, n}=$ $\bar{V}_{X, n}=V_{T, n}$. The optimal levels of search effort $\mathbb{S}_{n}$ solve first-order conditions that are similar to (6). They are stated in Appendix C. They imply that $s_{X, n}>s_{U, n}$ because the unemployed in the second tier gain more from searching $\left(V_{E, n}-V_{X, n}>V_{E, n}-V_{U, n}\right)$. On the contrary, $s_{T, n}$ and $s_{U, n}$ cannot be ranked. The treated are induced to search

\footnotetext{
${ }^{12}$ In Continental Europe, it is quite natural to assume that the expected length of an employment spell (taking all types of contracts into account) is longer than the expected duration of the shortduration ALMP.
} 
harder because search effort is more efficient $\left(c_{T, n}>c_{n}\right)$. However, when search is successful, the net gain is lower for the treated: $V_{E, n}-V_{T, n}<V_{E, n}-V_{U, n}$.

Job creation is modelled in the same way as in Section 2.1. Thus, the vacancy-supply curve (9) remains unchanged. Since the expression relating $V_{U, n}$ to the endogenous variables and the parameters is much more complex than in Section 2.1, the "wage-setting curve" is more involved, too (see (52) in Appendix C). However, the properties found earlier remain. The net wage $w_{n}$ is an increasing function of tightness $\theta_{n}$. Marginal changes in job-search effort do not shift the wage-setting curve. The equations that characterize search effort levels in equilibrium are much more complex than (12). They are stated in Appendix C. It remains true that search effort increases with tightness and decreases with the tax rate $\tau_{n}$.

Eliminating the net wage from the wage-setting and the vacancy-supply curves yields a system of equations $\mathbb{G}_{l}=\mathbb{G}_{h}=0$. As in Section 2.1, each of these equalities define an increasing implicit relationship between $\theta_{l}$ and $\theta_{h}$. It can easily be seen that the employment tax $a_{n}$ and the tax rate $\tau_{n}$ play qualitatively the same role as in Section 2.1 .

The equilibrium effects of the parameters characterizing the unemployment insurance system and the ALMP have already been developed under the M-P assumption. ${ }^{13}$ Here, we briefly summarize theses effects and then explain how the comparative statics changes in our more flexible setting. We focus on two major parameters only: $\pi_{n}$ and $\gamma_{n}$.

In a two-tiered unemployment benefit scheme, Van der Linden (2003a) shows that a marginal increase in the rate $\left(\pi_{n}\right)$ at which jobless workers flow from the high to the low benefit levels raises tightness (via a decrease in the fall-back position of the workers) but it has an ambiguous impact on employment. Three different mechanisms are at work: 1) since $s_{X, n}>s_{U, n}$, a positive direct effect (i.e., conditional on $\theta_{n}$ ); 2) A positive indirect effect via the increase in tightness; 3) A negative "entitlement effect" (see Mortensen 1977). ${ }^{14}$

In our more flexible setting, not only the effect on employment but also the one on tightness are ambiguous in sector $n$. The above-mentioned direct effect and the entitlement effect influence $E_{n}$ in opposite ways. If the entitlement effect is dominated by the other one ${ }^{15}$ the rise in employment lowers the price of the intermediate good. So, in a $\left(\theta_{n}, w_{n}\right)$ space, the vacancy-supply curve shifts downwards. This move and the downward shift of the wage-setting curve explain why the net effect on $\theta_{n}$ is now

\footnotetext{
${ }^{13}$ See Van der Linden (2003a), Van der Linden (2003b), and Van der Linden (2005).

14 The gain of a successful search activity also depends on the utility if the new job is lost. This gain is negatively affected by $\pi_{n}$.

15 That is, if $\frac{\partial E_{n}}{\partial \pi_{n}}+\sum_{\iota \in U, X, T} \frac{\partial E_{n}}{\partial s_{\iota, n}} \frac{\partial s_{\iota, n}}{\partial \pi_{n}}>0$. Although there is no formal proof, this sounds plausible because the entitlement effect is a delayed effect if the worker returns in unemployment.
} 
ambiguous. In addition, the variation of $E_{n}$ has an induced effect on tightness in the other sector. This mechanism has already been explained in Section 2.1. If the entitlement effect is dominated by the other one, a rise in $\pi_{n}$ would unambiguously increase equilibrium tightness in the other sector. ${ }^{16}$ Recall that this cross-effect does not appear under the M-P assumption.

Van der Linden (2005) shows that a marginal rise in the rate of entry into the ALMP, $\gamma_{n}$, has has a clear-cut negative impact on tightness but an unclear net effect on employment. ${ }^{17}$ Tightness decreases because increasing $\gamma_{n}$ has a wage-push effect (since $\left.V_{T, n}>V_{U, n}\right)$ and no effect on the vacancy-supply curve under the M-P assumption. Employment is influenced by $\gamma_{n}$ via three effects: 1) a positive direct effect if, as we assume for the rest of this section, the "matching effectiveness" $c_{T, n} s_{T, n}$ is sufficiently higher than $c_{n} s_{X, n}{ }^{18}$;2) A negative effect via tightness and, in turn, search effort; 3) A direct negative effect on search effort in state $X_{n}$ and a positive direct effect on search effort in state $T_{n}$.

Now, in our more flexible setting, not only the effect of employment but also the one on tightness are in general ambiguous because, under the M-P assumption, the net effect of $\gamma_{n}$ on $E_{n}$ is ambiguous (see Appendix D). However, if this effect is nonnegative, Appendix $\mathrm{D}$ shows that $d \theta_{l} / d \gamma_{l}<0$ and $d \theta_{h} / d \gamma_{h}<0$ in our more flexible setting.

The model of Section 2.1 is in addition extended to deal with the extensive margin (participation decisions). Furthermore, the government budget constraint is added to close the model. Participation is modeled as in Pissarides (2000). Inactive people have an arbitrage condition: Staying inactive or entering state $X_{n} \cdot{ }^{19}$ Let $\mathcal{P}_{n}$ be the exogenous size of the working age population $\left(\mathcal{P} \equiv \sum_{n} \mathcal{P}_{n}\right)$. Let $\left[V_{1, n}, V_{2, n}\right]$ be the finite support of the distribution of intertemporal utility levels in inactivity, $V_{I, n}$. With a uniform distribution, the participation rate is simply defined as:

$$
p_{n} \equiv \frac{L_{n}}{\mathcal{P}_{n}}=\frac{V_{X, n}-V_{1, n}}{V_{2, n}-V_{1, n}} .
$$

The budget of the State scaled by $\mathcal{P}$ can be written as follows:

$$
O+\sum_{n}\left(\rho_{U, n} u_{n}+\rho_{X, n} x_{n}+\left(\rho_{T, n}+C\right) t_{n}\right) p_{n} \mathcal{P}_{n}=\sum_{n}\left(a_{n}+\tau_{n} w_{n}\right) e_{n} p_{n} \mathcal{P}_{n}
$$

${ }^{16}$ The proof which makes use of Euler's formula is available upon request.

17 The same kind of reasoning holds in case of a decline in the failure rate, $\lambda_{n}$.

18 The matching effectiveness of those in the first tier $\left(U_{n}\right)$ can be raised either by sending them into the active program or by letting them enter the second tier $\left(X_{n}\right)$. Independently of the induced effects, the active program cannot raise employment if the former channel is less effective than the latter (i.e., if $c_{T, n} s_{T, n}<c_{n} s_{X, n}$ ). See Appendix D for details.

${ }^{19}$ Alternatively, they could enter uninsured unemployment. In many countries, they would have access to a minimum income guarantee. The latter is in a way or another related to the lowest level of UBs. 
where $u_{n}=U_{n} / L_{n}, x_{n}=X_{n} / L_{n}, t_{n}=T_{n} / L_{n}, e_{n}=E_{n} / L_{n}, C$ is the average cost of the program and $O$ is an exogenous level of net public expenses. The introduction of a binding budget condition does not allow to get clear-cut comparative static results. We therefore turn now to a simulation exercise. The latter will introduce a normative criterion. With risk-neutral agents and in the absence of a concern for redistribution, we consider a benevolent planner who at any moment $t$ maximizes

$$
\int_{t}^{+\infty} e^{-r(\tilde{t}-t)} W(\tilde{t}) d \tilde{t}
$$

where $W(\tilde{t})$ is the sum of the instantaneous income of the individuals (weighted by their numbers) and of profits made by the final and the intermediate firms. Under the budget constraint (28) and the assumption that the discount rate tends to zero, this benevolent planner actually maximizes net output in steady state:

$$
F\left(E_{l} y_{l}, E_{h} y_{h}\right)-\sum_{n}\left(U_{n} d\left(s_{U, n}\right)+X_{n} d\left(s_{X, n}\right)+T_{n} d\left(s_{T, n}\right)\right)-\sum_{n} k_{n} V_{n} .
$$

\section{Calibration, validation and extensions}

We take the month as unit of time. Data refer mostly to 1997 where the stocks of people in the various states were fairly stable in Belgium. It should be stressed at the outset that we do not have access to individual data about (non-)participants to LMPs nor to a pilot-study. Long-term unemployment is a major problem in Belgium. During the last thirty years or so, more than $50 \%$ of the stock has typically been unemployed for more than a year. The median duration in the stock amounts to about 2 years. In Belgium, negative duration dependence is very strong but Cockx and Dejemeppe (2005) have shown that it is largely spurious in the South. On data covering the period 1995 - 2004, Heylen and Bollens (2006) find positive duration dependence for men (nearly no dependence for women) in the North of the country. Their result for men is in accordance with our theoretical model. The level of skill (understood as education) is one of the key individual characteristics that affect the hiring rate. In each region of the country and for each gender, the unemployment rate of the lesseducated (at most a lower-secondary degree) is for many years two to four times higher than the one of those with post-secondary education. Due to statistical availability, only two levels of skill are distinguished. The low-skill population is assumed to hold at most a lower-secondary degree. The low-skilled represent $34 \%$ of the active population, $30 \%$ of salaried employment and $64 \%$ of the stock of unemployed. Table 1 presents the calibrated values and the rates of people in the various states. The low-skilled total unemployment rate is about $20 \%$ against $6.5 \%$ for the skilled workers. The ratio between salaried employment and the active population, $e$, and the participation rate, $p$, are much lower for the low-skilled. 


\section{Table 1 about here}

As far as the lowest wages are concerned, European countries can be broadly split in two groups: Those with a legal minimum wage fixed by the government and those without it. In the latter case, collective agreements determine the lowest wages. Belgium is an exception. There is a legal minimum gross monthly income that is negotiated by social partners. Moreover, minimum monthly or hourly wages are negotiated at the sectorial level and are typically above the legal minimum income. The theoretical model where all wages are bargained over is therefore appropriate.

To calibrate the model, we first exploit relationships derived from the model (equilibrium of flows in steady-state, the wage-setting curves, the optimality conditions). We also make use of various surveys ${ }^{20}$, published statistics, ${ }^{21}$ other statistics collected for the purpose of this study, and results from the literature. A sensitivity analysis is conducted on some parameters.

We take $a_{h}=a_{l}=0$. Data on wage costs and net wages are used to fix the tax rate (including social security contributions) $\tau_{n}$. These are high $\left(\tau_{l}=1, \tau_{h}=1.17\right)$. The main features of an unemployment benefit (UB) system are the eligibility and end-ofentitlement rules and the time profile of UBs. Administrative data indicate that less than $2.5 \%$ of the unemployed do not receive unemployment benefits (UBs) in Belgium. In 1998, less than $2 \%$ of the unemployed have lost their entitlement (after a very long spell of unemployment). So, the model of the previous section is a good approximation of the Belgian UB system. As far as the profile of UBs is concerned, there is first a period of one year where UBs stay constant. With the month as unit of time, $\pi_{n}$ is therefore set equal to 0.083. For about two-third of the insured unemployed, the level of benefits decreases afterwards. For the others, UBs are flat. The time-profile of skillspecific UBs is an average of the various profiles computed from administrative data. The net ${ }^{22}$ replacement ratios are displayed in Table 1 . At the end of the nineties, many beneficiaries of active programs participated (often simultaneously) to a combination of three interventions (Vos, Struyven and Bollens 2000): Individual advice and guidance, ${ }^{23}$ job-search assistance (such as job clubs, tips on finding jobs and writing a successful resume) and short-duration vocational training. ${ }^{24}$ Due to constraints on data, those policies are taken as an aggregate and henceforth called 'counseling programs'.

\footnotetext{
20 Simoens, Denys and Denolf (1998) Denolf, Denys and Simoens (1999) and Delmotte, Van Hootegem and Dejonckheere (2001).

21 Published by national and regional PES in Belgium and by Eurostat (2002a) and Eurostat (2002b).

22 The unemployed who live only on UBs do not pay income taxes in Belgium.

23 "Plan d'accompagnement des chômeurs" i.e., a small number of meetings with a member of the PES during a period of four months.

24 According to annual reports of the regional PES, there exist very short programs mixing counseling and short-lived training that lasted about 100 hours on average.
} 
As many other papers, let us assume the following Cobb-Douglas matching function (see Petrongolo and Pissarides 2001): $m\left(S_{n}, V_{n}\right) \equiv m_{0} S_{n}^{0.5} V_{n}^{0.5}$. Parameter $m_{0}$ is a scaling factor for the various $c_{\iota}$ 's and for $k_{n}{ }^{25}$ The discount rate is fixed at $0.004(5 \%$ on an annual basis). Annual reports of the PES allow to fix parameters $\phi_{n}, \lambda_{n}$ and $\gamma_{n}$ (see Table 1).

The expected duration of a vacancy (2.5 month) and the share of the low-skilled in the total number of recruitments (0.38) is used to calibrate the $\theta$ 's. The aggregate production function is a C.E.S. Due to a lack of appropriate time-series for Belgium, we use a French study (Biscourp and Gianella 2001) to fix the elasticity of substitution to 1.1. The "vacancy-supply curves" (9) are then used to calibrate the $k$ 's. The unobserved vacancy costs can be interpreted as a black-box capturing search, screening and training costs incurred by firms to recruit workers. More generally, they implicitly also include all other set-up costs incurred in order to create the job. This explains why the calibrated values of the cost $k_{n}$ are often large in the literature when the capital stock is ignored. ${ }^{26}$ The marginal products $p_{n} y_{n}$ are chosen so as to produce sensible values for the ratio of the share of the wage bill in output.

We assume an iso-elastic cost of job-search $d(s)=\psi_{n} s^{\xi_{n}} / \xi_{n}$, with $\psi_{n}>0$ and $\xi_{n}>$ 1. The products $c_{\iota} s_{\iota}, \iota=\{T, n\},\{X, n\},\{U, n\}, n \in\{l, h\}$ can be computed from the flow equilibrium conditions. Conditional on these products, the calibration then fixes the $c_{\iota}$ 's, the $s_{\iota}$ 's, $\xi_{n}$, and the bargaining power of the workers $\beta_{n}$. This part of the calibration is based on Equations (52), (53), (54) and (55) in Appendix C. Raising parameters $\psi_{n}$ induces a proportional increase in $c_{T, n}$ and $c_{n}$ and a proportional reduction in all search-effort levels without affecting the other parameters. So, we adopt the following normalization: $\psi_{l}=\psi_{h}=e^{2}$. From Table 1, an increase in $\gamma_{n}$ has a direct positive effect on employment. Skilled workers search more intensively. As expected, they have higher matching effectiveness parameters.

The bargaining power of the skilled workers happens to verify the Hosios condition. In an economy without taxes, the calibrated bargaining power would lead to an inefficiently high level of unemployment for the low-skilled. ${ }^{27}$

Following Immervoll, Kleven, Thurstup Kreiner and Saez (2004), the elasticity of the participation rate $p_{n}$ with respect to $w_{n}$ is fixed to 0.4 for the low-skilled and 0.2 for the high-skilled. These assumptions and the participation rates allow to calibrate

\footnotetext{
${ }^{25}$ Assuming that $m_{0}=0.5$ yields reasonable values. A sensitivity analysis has been conducted. We consider an alternative matching function, inspired by the results of Cockx and Dejemeppe (2002), namely $m_{0} S_{n}^{0.4} V_{n}^{0.6}$. Unreported simulation results show that the effects of changes in the tax wedge are similar.

${ }^{26}$ See also Fredriksson and Holmlund (2001) and the references cited in their footnote 20.

${ }^{27}$ One can wonder why $\beta_{l}$ is somewhat higher than $\beta_{h}$ in Table 1 . Union density is one of the determinants of the bargaining power. It turns out that union density is more important among blue-collar workers than among white-collar ones.
} 
the boundaries $V_{1, n}$ and $V_{2, n}$ in (27). Finally, from data in Eurostat (2002a, 2002b), the average cost $C$ is about 130 Euro per worker and per month (net of transfers to beneficiaries of the program).

To check the validity of this calibration, we look at two properties of the model that were not used during the calibration and about which some data are available. In 1997, the average stock of vacancies registered by the PES amounted to 24,500. With a market share of the PES in the range [0.4,0.5], the calibrated stock of vacancies $(53,000)$ is an acceptable order of magnitude. With the calibrated parameters, the expected duration of an unemployment spell amounts to 11 months for the skilled and 31 months for the low-skilled. Weighted by the share of each skill in the inflow into unemployment, the mean duration would then be equal to 19 months, a result that is in line with the computations of Dejemeppe (2005). ${ }^{28}$

The computed wage elasticity of salaried employment (job-search effort remaining fixed) amounts to low but reasonable values, namely - 0.54 for low-skilled workers and - 0.33 for skilled ones. We also consider later an elasticity of 2 instead of 1.1. After a new calibration, the two elasticities of labor demand become respectively equal to 0.65 and -0.34 . Finally, the elasticity of unemployment duration with respect to the level of UBs (tightness remaining fixed) is equal to 0.39 for the high-skilled and 0.26 for the low-skilled. The latter elasticities are relatively low but plausible. ${ }^{29}$

\section{Simulation results}

In this section, we illustrate by how much the effects of an employment subsidy on the low-skilled, $a_{l}$, change when the M-P assumption is replaced by our more flexible setting. Then, we look for the optimal level employment subsidy. Finally, we consider the interactions between an employment subsidy and other LMPs. When the budget constraint is binding in the simulation exercises, both tax rates $\tau_{n}$ are adjusted proportionally to fulfill (28).

Table 2 considers an employment subsidy $a_{l}=-300$ Euro/month, i.e., $12 \%$ of the calibrated wage cost. It seems to us important to measure the differences between the two models independently of a specific assumption about how the budget of the State is balanced. So, at this stage, the tax rates $\tau_{n}$ remain at their calibrated values. Comparing the case where the marginal values of labor are fixed (the M-P assumption) to the one where they vary lead to relatively small differences in tightness but large ones in search effort. Assuming fixed marginal values of labor leads to overestimate the level of employment $E_{l}$ by about $5 \%$ and to underestimate $E_{h}$ by $0.7 \%$ (see the two first lines

\footnotetext{
${ }^{28}$ From her analysis of unemployment dynamics in Belgium, the average unemployment duration all along the period 1987 - 1992 was close to 2 years in the South of Belgium and to 1.5 years in the North.

${ }^{29}$ According to Meyer (2002), an elasticity of 0.5 is a standard order of magnitude.
} 
of Table 2). Taking into account the differences in terms of the net wages, the over- and underestimations are more substantial in the case of intertemporal discounted values. As expected, the differences shrink when the elasticity of substitution, $\sigma$, increases. The magnitude of the over- and underestimations vary with the size of the employment subsidy. This is illustrated by Figure 3 that plots several indicators as a function of $a_{l}$. In this figure, both tax rates $\tau_{n}(n \in\{l, h\})$ are now adjusted to balance the budget of the State. This figure only displays search effort levels and the intertemporal discounted values in a single state (namely, $U_{n}, n \in\{l, h\}$ ) because the profiles in other states are very similar. The profile of $\tau_{h}$ is by construction the same as the one of $\tau_{l}$ and is therefore not displayed.

Figure 3 and Table 2 about here

Table 2

Properties when the marginal values of labor are fixed (the M-P assumption) and when they vary: The case of an employment subsidy $a_{l}=-300$ Euro/month when the budget of the State (28) is ignored

\begin{tabular}{cccccccccc}
\hline & & $\theta$ & $E$ & $w$ & $s_{U}$ & $s_{X}$ & $r V_{E}$ & $r V_{U}$ & $r V_{X}$ \\
\hline$\sigma=1.1$ & $l$ & +1.95 & +4.97 & +3.90 & +11.43 & +11.43 & +5.15 & +6.10 & +6.13 \\
& $h$ & -0.43 & -0.66 & -1.39 & -2.40 & -2.44 & -1.64 & -1.86 & -1.87 \\
$\sigma=2$ & $l$ & +1.25 & +3.18 & +2.53 & +7.22 & +7.22 & +3.33 & +3.93 & +3.95 \\
& $h$ & -0.28 & -0.43 & -0.91 & -1.58 & -1.61 & -1.08 & -1.22 & -1.23 \\
\hline
\end{tabular}

Note: The elasticity of substitution of the C.E.S. $\sigma=1.1$ or 2 . Relative differences in $\%$.

From now on, $\sigma=1.1$. Next, we look for the optimal employment subsidy taking the other parameters of the model unchanged. This task can be divided in two steps. First, the choice of the eligible population. Second, conditional on this choice, the level of the employment subsidy $a_{n}$. All simulations made lead to one first conclusion: Targeting the employment subsidy on the low-skilled is the best thing to do. To illustrate this assertion, consider the following comparison. An employment subsidy scheme $\left(a_{l}=-300, a_{h}=0\right)$ Euro/month is compared to a scheme that has the same cost ex ante (wages and employment being fixed) and a structure similar to current practices in Belgium, namely $\left(a_{l}=-110, a_{h}=-81\right) .{ }^{30}$ Taking the budget constraint

\footnotetext{
${ }^{30}$ Section 3 of Cardullo and Van der Linden (2006) provides more information about the Belgian policy.
} 
(28) into account, the first scheme clearly performs much better (see Table 3). ${ }^{31}$ So, from now on, we put $a_{h}$ to zero and focus on $a_{l}$ only.

Table 3 about here

Table 3

Comparing the properties of two employment subsidy schemes: $\left(a_{l}=-300, a_{h}=0\right)$ Euro/month (line 1) and $\left(a_{l}=-110, a_{h}=-81\right)$ Euro/month (line 2) when the budget of the State (28) is binding. Relative differences in \%.

\begin{tabular}{ccccccccc}
\hline$\%$ & $E_{l}$ & $E_{h}$ & $w_{l}$ & $w_{h}$ & $r V_{E, l}$ & $r V_{E, h}$ & $r V_{U, l}, r V_{X, l}$ & $r V_{U, h}, r V_{X, h}$ \\
\hline$(1)$ & +11.6 & +1.4 & +8.8 & +3.4 & +11.6 & +3.8 & +13.7 & +4.2 \\
$(2)$ & +5.0 & +1.2 & +2.6 & +2.7 & +3.5 & +3.2 & +4.2 & +3.7 \\
\hline
\end{tabular}

Let us now look at the optimal value of $a_{l}$. The criterion of optimality, $Y$, is net output in steady state (30) scaled by the size of the population. ${ }^{32} Y$ reaches a maximum when $a_{l}$ is close to - 1490 Euro/month (see Figure 3). We also compute net output assuming fixed marginal values of labor and find a maximum that lies out of the range of values considered in Figure 3, namely close to $a_{l}=-2430$ Euro/month. So, the normative conclusion appears to be very different whether marginal values of labor are assumed to be fixed or not.

The optimal employment subsidy looks extremely large compared to the calibrated value of the net wage (1229 Euro/month). Through bargaining, the employment subsidy is to some extent appropriated by the low-skilled workers. When $a_{l}=-1490$, the net monthly wage amounts to 1677 Euro $(+36 \%)$. Thanks to a cut in unemployment (the low-skilled unemployment rate is halved), the rise in the tax rate needed to finance the subsidy $(11 \%)$ is not huge. Altogether, the optimal low-skilled wage cost is equal to 2053 Euro (16\% lower than the calibrated wage cost, 2258 Euro). The optimal total amount of taxes (income taxes and social security contributions) paid on low-skilled work equals 376 Euro (i.e., 70\% lower than without the employment subsidy). By comparison with current policies, consider a low-skilled single person without children.

\footnotetext{
${ }^{31}$ It is not obvious that even the high skilled prefer the first scheme to the second one. For, the latter would a priori raise their bargained wage and their employment rate more than the first scheme. However, the lower global effect of the second scheme on (un)employment leads to higher tax rates $\tau_{n}, \forall n \in\{l, h\}$. And this effect turns out to outweigh the others. Unreported simulation results indicate that the advantage of targeting employment subsidies on low-skilled workers remains when $\sigma$ increases.

32 Since our calibration uses a discount rate of 0.004 , a fully rigorous analysis would require to look also at the adjustment path towards the steady-state values.
} 
The corresponding average total amount of taxes is about 850 Euro/month in 2005 . In the case of a couple with two children and a single (low-skilled) wage, the average total amount of taxes is about 620 Euro/month in 2005. So, the gap between current and optimal levels of taxes on low-skilled workers is still large.

Adopting a political economy perspective, it is however doubtful that the optimal value of $a_{l}$ would be implemented. For, the skilled workers, who represent two-third of the active population, first benefit from the employment subsidy but start losing below $a_{l} \approx-600$ Euro (See Figure 3). The relationship between the tax rates $\tau_{n}$ and $a_{l}$ is U-shaped. For sufficiently small values of $a_{l}$, the employment subsidy is so effective that the tax rates $\tau_{n}$ can be slightly reduced. Above an employment subsidy $\approx 370$ Euro/month, the tax rates $\tau_{n}$ start rising. So, on the one hand there is the favorable effects of $a_{l}$ on tightness $\theta_{h}$ explained in Section 2.1 and on the other the rise in the tax rate $\tau_{h}$ eventually reduces the net wage and the employment level of the high-skilled. ${ }^{33}$ Their intertemporal discounted income starts shrinking, too.

The previous simulation exercise illustrates that "countries can engineer a reduction of unemployment without a sacrifice of low-end pay and a rise in low-end pay without a sacrifice of employment" (Phelps 2003, p. 11). We now consider interactions between fiscal instruments and other LMPs and raise the question: Could reforms to LMPs improve the effectiveness of employment subsidies? Public expenditures on LMPs represented $3.75 \%$ of GDP in Belgium in 2003. Is it possible to engineer reforms to LMPs that reduce public expenditures but reinforce the effects of an employment subsidy and are welfare improving (at least in steady state)? To answer that question, we consider a reform that induces steeper time-profile of UBs (a rise in parameter $\pi_{n}$ ) and another that lowers the rate of entry into the active program, $\gamma_{n}$. Below, we consider an employment subsidy $a_{l}=-300$ Euro/month. According to Figure 3, such a subsidy improves the intertemporal utility of all individuals. Moreover, with $a_{l}=-300$, the ex ante cost of the subsidy equals $1 \%$ of GDP, i.e., the total amount of reductions in employers' payroll taxes in Belgium in 2003. Given the huge public debt of this country, keeping total (ex ante) expenses constant looks reasonable.

At given tax levels, Section 2.2 indicated that a rise in $\pi_{n}$ would have a clear-cut negative effect on net wages and ambiguous effects on tightness and employment. If this reform allows to reduce the tax wedge, the effect on the wage could however be reversed. This is illustrated by the following simulation. Let us compare the status quo

\footnotetext{
${ }^{33}$ For negative values of $a_{l}$ close to zero, Figure 3 indicates that $\theta_{h}$ actually declines when $a_{l}$ becomes more negative. Two effects are at work. First, as we saw in Section 2.1, conditional on $\tau_{n}, n \in\{l, h\}$, both tightness levels increase when $a_{l}$ becomes more negative. Second, if the tax rates $\tau_{n}, n \in\{l, h\}$, decline, it can be checked that both levels of tightness decline too and conversely (see (23)). In the case of the high-skilled segment, the second effect outweighs the former for negative values of $a_{l}$ close to zero.
} 
as far as $\pi_{n}$ is concerned with a subsidy $a_{l}=-300$ and a reform that simultaneously introduces the subsidy $a_{l}=-300$ and a higher rate of loss of high benefits (namely, $\left.\pi_{n}=1 / 3, \forall n \in\{l, h\}\right)$. When $a_{l}=-300$, total net output, $Y$, is $2 \%$ higher when $\pi_{n}=1 / 3$ : 2137 Euro instead of 2095. The tax rates $\tau_{n}$ can be reduced (for instance, $\tau_{h}$ equals 1.07 when $\pi_{n}=1 / 3$ versus 1.13 when $\left.\pi_{n}=1 / 12\right)$. Without this tax reduction, the low-skilled, whatever their current position, would be worse-off when $\pi_{n}=1 / 3$, while the high-skilled would be better-off. Compared to $\left(\pi_{n}=1 / 12, a_{l}=-300\right)$, Table 4 shows that the reform $\left(\pi_{n}=1 / 3, a_{l}=-300\right)$ becomes a steady-state Pareto improvement when tax rates are adjusted (downwards) to fulfill the budget constraint (28). Unreported simulations results show that this conclusion is robust to changes in the discount rate. To check this, we considered an annual discount rate of $20 \%$ (instead of $5 \%$ ), we calibrated the model again and then simulated it. Remember however that the model assumes risk neutrality.

Van der Linden (2005) studies the effect of an active program that enhances matching effectiveness. In a framework where the marginal values of labor are fixed, his simulation exercise for Belgium leads to mixed conclusions with respect to the rate of entry into the active program. (Un)employment deteriorates with $\gamma_{l}$ while the lowskilled intertemporal indicators of welfare are improving. In addition, the welfare of the high-skilled is negatively affected by a rise in the size of the program. Given these results, we here compare the performances of $a_{l}=-300$ when $\gamma_{l}$ is left unchanged with the case where this program is abandoned. In the latter case, net output is larger (2131 Euro versus 2095 with the active program). The tax rate is reduced $\left(\tau_{h}=1.08\right.$ instead of 1.13). Table 5 indicates that again net wages, employment and utility levels can simultaneously increase if the active program analyzed here disappears as the employment subsidy is introduced.

These simulation exercises have illustrated the existence of reforms to LMPs that at the same time reduce public expenditures and improve the effects of an employment subsidy.

Tables 4 and 5 about here 
Table 4

Properties of an employment subsidy $a_{l}=-300$ Euro/month when the budget of the State (28) is balanced and the expected duration of "high" benefits, $1 / \pi_{n}$, equals 12 or 3 months.

\begin{tabular}{ccccccc}
\hline & & $e$ & $w$ & $r V_{E}$ & $r V_{U}$ & $r V_{X}$ \\
\hline$\pi_{n}=1 / 12$ & $l$ & 0.647 & 1337 & 960 & 792 & 788 \\
$\pi_{n}=1 / 3$ & $l$ & 0.659 & 1368 & 981 & 809 & 807 \\
$\pi_{n}=1 / 12$ & $h$ & 0.754 & 1562 & 1306 & 1136 & 1130 \\
$\pi_{n}=1 / 3$ & $h$ & 0.762 & 1617 & 1354 & 1178 & 1176 \\
\hline
\end{tabular}

Table 5

Properties of an employment subsidy $a_{l}=-300$ Euro/month when the budget of the State (28) is balanced and the active program is either present or abandoned.

\begin{tabular}{ccccccc}
\hline & & $e$ & $w$ & $r V_{E}$ & $r V_{U}$ & $r V_{X}$ \\
\hline With active program & $l$ & 0.647 & 1337 & 960 & 792 & 788 \\
Without & $l$ & 0.658 & 1365 & 981 & 810 & 805 \\
With active program & $h$ & 0.754 & 1562 & 1306 & 1136 & 1130 \\
Without & $h$ & 0.761 & 1606 & 1344 & 1169 & 1163 \\
\hline
\end{tabular}

\section{Conclusion}

This paper has shown that the equilibrium search-matching model can be enriched to become an instrument of evaluation of policies targeted on specific groups. Instead of assuming a juxtaposition of labor markets, we have modelled interactions between them. The marginal value of labor then varies with the number of workers in all sectors. This paper shows that the model remains tractable. Several analytical conclusions can still be derived. For policy evaluations, the model has afterwards been extended to deal with institutional features and various labor market policies.

Using this framework, computational experiments have shown that employment subsidies targeted on low-skilled workers perform well. At least in countries with large tax wedges, they can simultaneously raise employment, wages and intertemporal income levels of all groups. This conclusion is in accordance with those of Drèze and Malinvaud et al. (1994), Phelps (1997) and Mortensen and Pissarides (2003). We have 
also illustrated that the efficiency of employment subsidies can be reinforced by reforms to active and passive labor market policies. We have developed an extensive sensitivity analysis which suggests that these conclusions are robust.

There are some caveats to add concerning the following limitations of our theoretical framework. First, employment subsidies influence training and schooling decisions made by individuals and firms (Blundell, Costa-Dias and Meghir 2003). Second, employment subsidies affect job destruction rates (Mortensen and Pissarides 2003). If they are targeted on low productivity jobs, such subsidies have a clear-cut negative effect on job destruction rates. Third, there is evidence that skilled workers supply labor on less-skilled labor markets (ladder effect) and that this phenomenon reduces the effectiveness of employment subsidies (Batyra and Sneessens 2007). These two last features have been combined in the model of Pierrard (2005), who concludes that employment subsidies targeted on low-paid workers have substantial positive effects on employment and on welfare. Fourth, it has been argued that employment subsidies targeted on low-skilled workers lock them in low-paid jobs. A model with on-the-job search and additional skill categories could take such an effect into account. Finally, for several years now, countries such as France, Germany, The Netherlands and Belgium have played a non-cooperative game to maintain their competitiveness. Cuts in payroll

taxes are among the instruments used. Our analysis has only been conducted for a single economy.

\section{References}

Acemoglu, D. (2001) "Good jobs versus bad jobs". Journal of Labor Economics, 19:1-21.

Albrecht, J., G. van den Berg and S. Vroman (2006) "The aggregate labor market effects of the Swedish Knowledge Lift program". Working Paper 2385, IZA, Institute for the Study of Labor, Bonn.

Albrecht, J. and S. Vroman (2005) "Equilibrium search with time-varying unemployment benefits". The Economic Journal, 115:631-648.

Batyra, A. and H. Sneessens (2007) "Selective reductions in labour taxation: Labour market adjustments and macroeconomic performace". Working Paper 2007-1, Department of Economics, Université catholique de Louvain, Belgium. 
Belot, M. and J. van Ours (2004) "Does the recent success of some OECD countries in lowering their unemployment rates lie in a clever design of their labour market reforms?" Oxford Economic Papers, 56:621-642.

Biscourp, P. and C. Gianella (2001) "Substitution and complementarity between capital, skilled and less skilled workers". Working Paper G 2001-13, INSEE, France.

Blundell, R., M. Costa-Dias and C. Meghir (2003) "The impact of human capital policies: A general equilibrium approach". Working Paper, Institute for Fiscal studies, London, UK.

Boone, J. and J. van Ours (2004) "Effective active labor market policies". Working Paper 1335, IZA, Institute for the Study of Labor, Bonn.

Boone, J. and J. van Ours (2004) "Effective active labor market policies". Working Paper 1335, IZA, Institute for the Study of Labor, Bonn.

Cahuc, P. and E. Lehmann (2000) "Should unemployment benefits decrease with unemployment spell?" Journal of Public Economics, 77:135-153.

Cahuc, P. and E. Wasmer (2001) "Does intrafirm bargaining matter in the large firm's matching model ?" Macroeconomic Dynamics, 5:742-747.

Cahuc, P. and A. Zylberberg (2004) Labor economics. MIT Press, Cambridge.

Cardullo, G. and B. Van der Linden (2006) "Employment subsidies and substitutable skills: An equilibrium matching approach substitutable skills: An equilibrium matching approach". Working Paper 2006-10, Department of Economics, Université catholique de Louvain, Belgium.

Cockx, B. and M. Dejemeppe (2002) "Do the higher educated unemployed crowd out the lower educated ones in a competition for jobs?" Working Paper 541, IZA, Institute for the Study of Labor, Bonn.

Cockx, B. and M. Dejemeppe (2005) "Duration dependence in the exit rate out of unemployment in belgium. Is it true or spurious?" The Journal of Applied Econometrics, 20:1-23.

Coe, D. and D. Snower (1997) "Policy complementarities: The case for fundamental reforms". IMF Staff Papers, 44:1-35.

Coles, M. and A. Masters (2006) "Optimal unemployment insurance in a matching equilibrium". Journal of Labor Economics, 24:109-138. 
Davidson, C. and S. Woodbury (1993) "The displacement effect of reemployment bonus programs". Journal of labor Economics, 11:575-605.

Dejemeppe, M. (2005) "A complete decomposition of unemployment dynamics using longitudinal grouped duration data". Oxford Bulletin of Economics and Statistics, $67: 45-70$.

Delmotte, J., G. Van Hootegem and J. Dejonckheere (2001) Les entreprises et le recrutement en Belgique en 2000. Hoger instituut voor de arbeid, Katholieke universiteit Leuven, Belgium.

Denolf, L., J. Denys and P. Simoens (1999) Les entreprises et le recrutement en Belgique en 1998. Hoger instituut voor de arbeid, Katholieke universiteit Leuven, Belgium.

Drèze, J. and E. Malinvaud et al. (1994) "Growth and employment, the scope for a European initiative". European Economy, 1:75-106.

Eurostat (2002a) Labour market policies: Expenditure and participants (European Union and Norway, data 1998). Eurostat, Luxembourg.

Eurostat (2002b) Labour market policy: Expenditure and participants - data 2000. Eurostat, Europena Social Statistics, Luxembourg.

Fredriksson, P. and B. Holmlund (2001) "Optimal unemployment insurance in search equilibrium". Journal of Labor Economics, 19:370-399.

Heckman, J., L. Lochner and R. Cossa (2003) Learning-by-doing versus on-the-job training: Using variation induced by the EITC to distinguish between models of skill formation. In E. Phelps, editor, Designing Inclusion: Tools to Raise Low-end Pay and Employment in Private Enterprise. Cambridge University Press, Cambridge.

Heylen, V. and J. Bollens (2006) "Een evaluatie van de effectiviteit van de vroegtijdige en sluitende aanpak van de werkloosheid in vlaanderen (2002-2004)". Working Paper 1051, Hoger Instituut voor de Arbeid, Katholieke Universiteit, Leuven,, Belgium.

Holmlund, B. (2002) "Labor taxation in search equilibrium with home production". The German Economic Review, 4:415-430.

Holmlund, B. and J. Lindén (1993) "Job matching, temporary public employment, and equilibrium unemployment". Journal of Public Economics, 51:329-343. 
Immervoll, H., H. Kleven, C. Thurstup Kreiner and E. Saez (2004) "Welfare reform in European countries: A micro-simulation analysis". Working Paper 4324, Centre for Economic Policy Research.

Joseph, G., O. Pierrard and H. Sneessens (2004) "Job turnover, unemployment and labor market institutions". Labour Economics, 11:451-468.

Machin, S. and A. Manning (1999) The causes and consequences of longterm unemployment in europe. In O. Ashenfelter and D. Card, editors, Handbook of Labor Economics, Volume 3C. Elsevier Science Publisher (North-Holland), Amsterdam.

Masters, A. (2000) "Retraining the unemployed in a model of equilibrium employment". Bulletin of Economic Research, 52:323-340.

Meyer, B. (2002) 'Unemployment and workers' compensation programmes: Rationale, design, labour supply and income support". Fiscal Studies, 23:1-49.

Mortensen, D. (1977) "Unemployment insurance and job search decisions unemployment insurance and job search decisions". Industrial and Labor Relations Review, 30:505-517.

Mortensen, D. and C. Pissarides (2003) Taxes, subsidies and equilibrium labour market outcomes. In E. Phelps, editor, Designing Inclusion: Tools to Raise Low-end Pay and Employment in Private Enterprise. Cambridge University Press, Cambridge.

Nickell, S. and R. Layard (1999) Labor market institutions and economic performance. In O. Ashenfelter and D. Card, editors, Handbook of Labor Economics, Volume 3C. Elsevier Science Publisher (North-Holland), Amsterdam.

OECD (2003) Employment outlook. OECD, Paris.

Orszag, J. and D. Snower (1998) "Anatomy of policy complementarities". Swedish Economic Policy Review, 5:303-345.

Petrongolo, B. and C. Pissarides (2001) "Looking into the black box: A survey of the matching function". Journal of Economic Literature, 39:390-431.

Phelps , E. (2003) Ed., Designing inclusion: Tools to raise low-end pay and employment in private enterprise. Cambridge University Press, Cambridge.

Phelps, E. (1997) Rewarding work : How to restore participation and self-support to free enterprise. Harvard University Press, Cambridge. 
Pierrard, O. (2005) "Impacts of selective reductions in labor taxation". Applied Economics Quarterly, 51:49-82.

Pissarides, C. (2000) Equilibrium unemployment theory. MIT Press, Cambridge (MA).

Rocheteau, G. (1999) "Balanced budget rules and indeterminacy of the equilibrium unemployment rate". Oxford Economic Papers, 51:399-409.

Rosholm, M. (2001) "Cyclical variations in unemployment duration". Journal of Population Economics, 14:173-191.

Simoens, P., J. Denys and L. Denolf (1998) Les entreprises et le recrutement en Belgique en 1997. Hoger instituut voor de arbeid, Katholieke universiteit Leuven, Belgium.

Stole, L. and J. Zwiebel (1996) "Intrafirm bargaining under non-binding contracts". Review of Economic Studies, 63:375-410.

van den Berg, G. and J. van Ours (1999) "Duration dependence and heterogeneity in french youth unemployment duration". Journal of Population Economics, 12:273-285.

Van der Linden, B. (2003a) "Unemployment insurance and training in an equilibrium matching model with heterogeneous agents". Working Paper 2003-01, CREST, INSEE, and Institut de Recherches Economiques et Sociales, Department of Economics, Université Catholique de Louvain, Malakoff (France) and Louvain-la-Neuve (Belgium).

Van der Linden, B. (2003b) "Unemployment benefit profile, monitoring and active labor market policies: The role of normative criteria". Working Paper 127, Chaire Hoover d'Ethique Economique et Sociale, Université catholique de Louvain, Belgium.

Van der Linden, B. (2005) "Equilibrium evaluation of active labor market programmes enhancing matching effectiveness". Working Paper 1526, IZA, Institute for the Study of Labor, Bonn.

Vos, S., L. Struyven and J. Bollens (2000) "Werk, werkloos, werk: effectiviteit en kostenbatenanalyse van reïntegratietrajecten voor werklozen". Working Paper, Hoger Instituut voor de Arbeid, Katholieke Universiteit, Leuven. 


\title{
Appendixes
}

\section{A Existence and Uniqueness of the Equilibrium}

\section{CASE 1: No balanced-budget constraint}

\author{
Existence and Uniqueness If $\forall(n, m), n \neq m \lim _{E_{n} \rightarrow 0} p_{m}>0$ and \\ $\lim _{E_{n} \rightarrow+\infty} p_{m}<+\infty$, there is a unique steady-state equilibrium.
}

From (12), search effort $s_{n}$ is an increasing function of $\theta_{n}, s_{n}=S\left(\theta_{n}\right)$. We substitute $S\left(\theta_{n}\right)$ into $\mathbb{G}_{n}=0$ and express $\mathbb{G}_{n}$ in terms of $\theta_{n}$ and $\theta_{m}, n \in\{l, h\}$ only $(n \neq m)$. $\mathbb{G}_{h}\left(\theta_{l}, \theta_{h}\right)=0$ implicitly yields a relationship $\theta_{h}=g_{h}\left(\theta_{l}\right)$ with $g_{h}^{\prime}\left(\theta_{l}\right)>0$ by (14) and (15). Similarly, $\mathbb{G}_{l}\left(\theta_{l}, \theta_{h}\right)=0$ implicitly defines a solution $\theta_{h}=g_{l}\left(\theta_{l}\right)$ with $g_{h}^{\prime}\left(\theta_{l}\right)>0$. Let $\theta_{l}=g_{h}^{-1}\left(\theta_{h}\right)$ and $\theta_{l}=g_{l}^{-1}\left(\theta_{h}\right)$ denote their inverse functions. Then, we define $H\left(\theta_{l}\right) \equiv g_{h}\left(\theta_{l}\right)-g_{l}\left(\theta_{l}\right)$. If $H\left(\theta_{l}\right)$ crosses the horizontal axis, the existence of (at least) one equilibrium is proved (steps 1 and 2 below). If $H\left(\theta_{l}\right)$ is in addition a monotonic function, the equilibrium is unique (step 3 below).

FIRST STEP: $H\left(\theta_{l}\right)$ is positive as $\theta_{l}$ tends to 0 .

As $\lim _{\theta_{n} \rightarrow 0} E_{n}=0$ and $\lim _{E_{n} \rightarrow 0} p_{m}>0(n \in\{l, h\})$, then $\lim _{\theta_{l} \rightarrow 0} g_{h}\left(\theta_{l}\right)=\chi_{h}>0$ and $\lim _{\theta_{h} \rightarrow 0} g_{l}^{-1}\left(\theta_{h}\right)=\chi_{l}>0$ (see Figure 1). Since $g_{l}^{\prime}\left(\theta_{l}\right)>0$, then $\lim _{\theta_{l} \rightarrow 0} g_{l}\left(\theta_{l}\right)<0$. So, $\lim _{\theta_{l} \rightarrow 0} H\left(\theta_{l}\right) \equiv g_{h}\left(\theta_{l}\right)-g_{l}\left(\theta_{l}\right)>0$.

SECOND STEP: $H\left(\theta_{l}\right)$ is negative for some positive value of $\theta_{l}$.

Since $\lim _{E_{l} \rightarrow+\infty} p_{h}<\infty$, we get $\lim _{\theta_{l} \rightarrow+\infty} g_{h}\left(\theta_{l}\right)=\Psi_{h}>0$ and $\lim _{\theta_{h} \rightarrow+\infty} g_{l}^{-1}\left(\theta_{h}\right)=$ $\Psi_{l}>0$ (see Figure 1). So, $\lim _{\theta_{l} \rightarrow \Psi_{l}} g_{l}\left(\theta_{l}\right)=+\infty$ and $\lim _{\theta_{l} \rightarrow \Psi_{l}} H\left(\theta_{l}\right) \equiv g_{h}\left(\theta_{l}\right)-$ $g_{l}\left(\theta_{l}\right)=-\infty$.

THIRD STEP: $H\left(\theta_{l}\right)$ is a decreasing function. $H^{\prime}\left(\theta_{l}\right)=g_{h}^{\prime}\left(\theta_{l}\right)-g_{h}^{\prime}\left(\theta_{l}\right)<0$ or equivalently:

$$
\left.\frac{d \theta_{h}}{d \theta_{l}}\right|_{\mathbb{G}_{l}=0}>\left.\frac{d \theta_{h}}{d \theta_{l}}\right|_{\mathbb{G}_{h}=0} \forall \theta_{l} .
$$

From (14) and (15), this condition can be written as:

$$
\left(A_{l}+B_{l}\right)\left(A_{h}+B_{h}\right)>C_{l, h} C_{h, l}
$$

From (17), (18) and the Euler's formula for linear homogeneous functions, it can be checked that $B_{l} B_{h}=C_{l, h} C_{h, l}$. So, remembering (16) and (17), inequality (31) is verified. 


\section{CASE 2: Sector specific balanced-budget conditions.}

Assume a specific budget constraint for each sector $n(n \in\{l, h\})$ :

$$
B_{n}\left(\theta_{n}, \tau_{n}\right) \equiv\left(a_{n}+\tau_{n} w_{n}\right) E_{n}-\rho_{n} w_{n}\left(L_{n}-E_{n}\right)=0
$$

where $w_{n}=W S\left(\theta_{n}\right)$ and $E_{n}=\mathbb{E}_{n}\left(\theta_{n}, S\left(\theta_{n}\right)\right)$. Then:

$$
\frac{d B_{n}}{d \theta_{n}}=\left(a_{n}+\tau_{n} w_{n}+\rho_{n} w_{n}\right)\left[\frac{\partial \mathbb{E}_{n}}{\partial \theta_{n}}+\frac{\partial \mathbb{E}_{n}}{\partial s_{n}} \frac{\partial s_{n}}{\partial \theta_{n}}\right]+\left[\tau_{n} E_{n}-\rho_{n}\left(L_{n}-E_{n}\right)\right] \frac{d W S_{n}}{d \theta_{n}}
$$

Such derivative is positive if $a_{n}+\tau_{n} w_{n}+\rho_{n} w_{n}>0$ and $\tau_{n} E_{n}-\rho_{n}\left(L_{n}-E_{n}\right)>0$, or one is equal to zero and the other is positive. The first condition seems plausible as long as $a_{n}$ is not too negative. The second condition is fulfilled if $a_{n}<0$. Moreover,

$$
\frac{d B_{n}}{d \tau_{n}}=w_{n} E_{n}+\left[a_{n}+\tau_{n} w_{n}+\rho_{n} w_{n}\right] \frac{\partial \mathbb{E}_{n}}{\partial s_{n}} \frac{\partial s_{n}}{\partial \tau_{n}}+\left[\tau_{n} E_{n}-\rho_{n}\left(L_{n}-E_{n}\right)\right] \frac{d W S_{n}}{d \tau_{n}} .
$$

The first term, representing the direct effect of an increase in $\tau_{n}$ on the budget of the State, is positive. The last two terms represent the induced effects of a higher $\tau_{n}$ on the budget. They are negative under the assumptions just made on the terms inside the square brackets. The sign of the derivative is therefore ambiguous. If we assume that the direct effect is stronger than the induced ones, then, applying the implicit function theorem $\left.\frac{d \theta_{n}}{d \tau_{n}}\right|_{\mathbb{B}_{n}=0}>0$. Hence, the budget constraint (33) defines a downward relationship $\tau_{n}=T\left(\theta_{n}\right)$. Then, we can show the following result:

Existence and Uniqueness $\quad$ If $\forall(n, m), n \neq m,\left.\frac{d \theta_{n}}{d \tau_{n}}\right|_{\mathbb{B}_{n}=0}>0, \lim _{E_{n} \rightarrow 0} p_{m}>0$, and $\lim _{E_{n} \rightarrow+\infty} p_{m}<+\infty$, there is a unique steady-state equilibrium in tightness levels.

Let us substitute $s_{n}=S_{n}\left(\theta_{n}\right)$ and $\tau_{n}=T\left(\theta_{n}\right)$ in $\mathbb{G}_{n}=0$. Then, instead of $(14)$, we have:

$$
\frac{d G_{n}}{d \theta_{n}}=A_{n}+B_{n}+D_{n}<0
$$

where $A_{n}+B_{n}<0$ (recall (16) and (17)) and $D_{n}=\left(1-\beta_{n}\right) d\left(s_{n}\right) \frac{d T_{n}}{d \theta_{n}}<0$. It is now easy to check that Steps 1 and 2 are the same as in the previous case. So at least an equilibrium exists. For the uniqueness, we still have to prove Inequality (31). When the budget of the state is introduced, this inequality becomes:

$$
\left.\frac{d \theta_{h}}{d \theta_{l}}\right|_{\mathbb{G}_{l}=0}=-\frac{B_{l}+A_{l}+D_{l}}{C_{l, h}}>-\frac{C_{h, l}}{A_{h}+B_{h}+D_{h}}=\left.\frac{d \theta_{h}}{d \theta_{l}}\right|_{\mathbb{G}_{h}=0} .
$$

The proof of this condition is as in Step 3. So, an equilibrium exists and is unique. 


\section{B Proof that $V_{T, n}>V_{U, n}>V_{X, n}$}

Let us recall the assumptions: $1>\rho_{T, n} \geq \rho_{U, n}>\rho_{X, n}, c_{T, n}>c_{n}, \gamma_{n} \geq 0, \lambda_{n} \geq 0, \pi_{n}>$ 0 . Let $b_{U, n}=\rho_{U, n} \cdot w_{n}+z_{n} . b_{X, n}$ and $b_{T, n}$ are defined similarly. We now distinguish the case where participation to the ALMP is chosen freely and the one where there is a treat to be sanctioned in case of refusal.

Case 1: Free participation $\left(\bar{V}_{U, n}=\max \left(V_{T, n}, V_{U, n}\right)\right)$

Let us prove that $V_{U, n}>V_{X, n}$. If $V_{U, n}$ was lower or equal to $V_{X, n}$ and $s_{U, n}$ was optimally chosen by the unemployed, the following inequalities would hold:

$$
\begin{aligned}
r V_{U, n}= & b_{U, n}-d\left(s_{U, n}\right)+c_{n} s_{U, n} \alpha\left(\theta_{n}\right)\left(V_{E, n}-V_{U, n}\right)+\gamma_{n}\left(\bar{V}_{U, n}-V_{U, n}\right)+\pi_{n}\left(V_{X, n}-V_{U, n}\right) \\
> & b_{X, n}-d\left(s_{X, n}\right)+c_{n} s_{X, n} \alpha\left(\theta_{n}\right)\left(V_{E, n}-V_{X, n}+V_{X, n}-V_{U, n}\right)+\gamma_{n}\left(\bar{V}_{U, n}-V_{U, n}\right) \\
& +\pi_{n}\left(V_{X, n}-V_{U, n}\right) \\
\geq & b_{X, n}-d\left(s_{X, n}\right)+c_{n} s_{X, n} \alpha\left(\theta_{n}\right)\left(V_{E, n}-V_{X, n}\right)+\gamma_{n}\left(\bar{V}_{U, n}-V_{U, n}\right)
\end{aligned}
$$

Several possibilities should be considered. Each of them should lead to a contradiction.

Case 1.1. $V_{T, n} \geq V_{X, n} \geq V_{U, n}$

Then, $\bar{V}_{U, n}=\bar{V}_{X, n}=V_{T, n}$. The RHS of (35) is higher than or equal to

$$
\begin{aligned}
& b_{X, n}-d\left(s_{X, n}\right)+c_{n} s_{X, n} \alpha\left(\theta_{n}\right)\left(V_{E, n}-V_{X, n}\right)+\gamma_{n}\left(\bar{V}_{U, n}-V_{X, n}\right) \\
= & b_{X, n}-d\left(s_{X, n}\right)+c_{n} s_{X, n} \alpha\left(\theta_{n}\right)\left(V_{E, n}-V_{X, n}\right)+\gamma_{n}\left(\bar{V}_{X, n}-V_{X, n}\right) \\
= & r V_{X, n}
\end{aligned}
$$

if $s_{X, n}$ is the optimal level of search (this condition is not recalled below). This leads to a contradiction. Therefore, $V_{U, n}>V_{X, n}$.

Case 1.2. $V_{X, n} \geq V_{U, n} \geq V_{T, n}$

Then, $\bar{V}_{U, n}=V_{U, n}$ and $\bar{V}_{X, n}=V_{X, n}$. The RHS of (35) is then equal to

$$
b_{X, n}-d\left(s_{X, n}\right)+c_{n} s_{X, n} \alpha\left(\theta_{n}\right)\left(V_{E, n}-V_{X, n}\right),
$$

which is again $r V_{X, n}$ because those in the second tier refuse to take part to the program. So, again, there is a contradiction. Therefore, $V_{U, n}>V_{X, n}$.

Case 1.3. $V_{X, n}>V_{T, n}>V_{U, n}$ 
The RHS of (35) is then equal to

$$
\begin{aligned}
& b_{X, n}-d\left(s_{X, n}\right)+c_{n} s_{X, n} \alpha\left(\theta_{n}\right)\left(V_{E, n}-V_{X, n}\right)+\gamma_{n}\left(V_{T, n}-V_{U, n}\right) \\
\geq & b_{X, n}-d\left(s_{X, n}\right)+c_{n} s_{X, n} \alpha\left(\theta_{n}\right)\left(V_{E, n}-V_{X, n}\right)=r V_{X, n}
\end{aligned}
$$

This leads once more to a contradiction. Therefore, $V_{U, n}>V_{X, n}$.

Knowing that $V_{U, n}>V_{X, n}$, let us now prove that $V_{T, n}>V_{U, n}$. If $V_{U, n}$ was higher than or equal to $V_{T, n}$ and $s_{T, n}$ was optimally chosen by the trainee, the following inequalities would be verified:

$$
\begin{aligned}
r V_{T, n} & =b_{T, n}-d\left(s_{T, n}\right)+c_{T, n} s_{T, n} \alpha\left(\theta_{n}\right)\left(V_{E, n}-V_{T, n}\right)+\lambda_{n}\left(V_{U, n}-V_{T, n}\right) \\
& \geq b_{T, n}-d\left(s_{U, n}\right)+c_{n} s_{U, n} \alpha\left(\theta_{n}\right)\left(V_{E, n}-V_{U, n}+V_{U, n}-V_{T, n}\right) \\
& >b_{U, n}-d\left(s_{U, n}\right)+c_{n} s_{U, n} \alpha\left(\theta_{n}\right)\left(V_{E, n}-V_{U, n}\right)+\pi_{n}\left(V_{X, n}-V_{U, n}\right)
\end{aligned}
$$

As $V_{T, n} \leq V_{U, n}, \bar{V}_{U, n}=V_{U, n}$. So, adding $\gamma_{n}\left(\bar{V}_{U, n}-V_{U, n}\right)$ to the RHS of (38) does not modify this expression. The RHS of (38) is then equal to $r V_{U, n}$. This leads to a contradiction. So, $V_{T, n}>V_{U, n}$.

Case 2: Participation under threat of a sanction in the first tier $\left(\bar{V}_{U, n}=\max \left(V_{T, n}, V_{X, n}\right)\right)$

Then, $\bar{V}_{U, n}=\bar{V}_{X, n}$. Let us prove that $V_{U, n}>V_{X, n}$. If $V_{U, n}$ was lower or equal to $V_{X, n}$ and $s_{U, n}$ was optimally chosen by the unemployed, the following inequalities would hold:

$$
\begin{aligned}
r V_{U, n}= & b_{U, n}-d\left(s_{U, n}\right)+c_{n} s_{U, n} \alpha\left(\theta_{n}\right)\left(V_{E, n}-V_{U, n}\right)+\gamma_{n}\left(\bar{V}_{U, n}-V_{U, n}\right)+\pi_{n}\left(V_{X, n}-V_{U, n}\right) \\
> & b_{X, n}-d\left(s_{X, n}\right)+c_{n} s_{X, n} \alpha\left(\theta_{n}\right)\left(V_{E, n}-V_{X, n}+V_{X, n}-V_{U, n}\right)+\gamma_{n}\left(\bar{V}_{U, n}-V_{U, n}\right) \\
& +\pi_{n}\left(V_{X, n}-V_{U, n}\right) \\
\geq & b_{X, n}-d\left(s_{X, n}\right)+c_{n} s_{X, n} \alpha\left(\theta_{n}\right)\left(V_{E, n}-V_{X, n}\right)+\gamma_{n}\left(\bar{V}_{U, n}-V_{X, n}+V_{X, n}-V_{U, n}\right) \\
\geq & b_{X, n}-d\left(s_{X, n}\right)+c_{n} s_{X, n} \alpha\left(\theta_{n}\right)\left(V_{E, n}-V_{X, n}\right)+\gamma_{n}\left(\bar{V}_{X, n}-V_{X, n}\right)=r V_{X, n},
\end{aligned}
$$

which leads to a contradiction. So, $V_{U, n}>V_{X, n}$.

To show that $V_{T, n}>V_{U, n}$, let us start from (38). Under the assumption that $V_{T, n}$ is lower than or equal to $V_{U, n}$, two sub-cases should be distinguished: $V_{T, n} \leq V_{X, n}<V_{U, n}$ and $V_{X, n}<V_{T, n} \leq V_{U, n}$.

Case 2.1 $V_{T, n} \leq V_{X, n}<V_{U, n}$ 
Since $V_{T, n} \leq V_{X, n}, \bar{V}_{U, n}-V_{U, n}=V_{X, n}-V_{U, n}<0$. All the unemployed reject the offers to take part to the program. Therefore, the RHS of (38):

$$
\begin{aligned}
& b_{U, n}-d\left(s_{U, n}\right)+c_{n} s_{U, n} \alpha\left(\theta_{n}\right)\left(V_{E, n}-V_{U, n}\right)+\pi_{n}\left(V_{X, n}-V_{U, n}\right) \\
\geq & b_{U, n}-d\left(s_{U, n}\right)+c_{n} s_{U, n} \alpha\left(\theta_{n}\right)\left(V_{E, n}-V_{U, n}\right)+\pi_{n}\left(V_{X, n}-V_{U, n}\right)+\gamma_{n}\left(\bar{V}_{U, n}-V_{U, n}\right) \\
= & r V_{U, n} .
\end{aligned}
$$

There is again a contradiction. So, $V_{T, n}>V_{U, n}$.

Case 2.2. $V_{X, n}<V_{T, n} \leq V_{U, n}$

Then $\bar{V}_{U, n}=\max \left(V_{T, n} ; V_{X, n}\right)=V_{T, n}$. Those who are in the first tier prefer to take

part to the program but they lose since $\bar{V}_{U, n}-V_{U, n}=V_{T, n}-V_{U, n}<0$. Therefore the RHS of (38):

$$
\begin{aligned}
& b_{U, n}-d\left(s_{U, n}\right)+c_{n} s_{U, n} \alpha\left(\theta_{n}\right)\left(V_{E, n}-V_{U, n}\right)+\pi_{n}\left(V_{X, n}-V_{U, n}\right) \\
\geq & b_{U, n}-d\left(s_{U, n}\right)+c_{n} s_{U, n} \alpha\left(\theta_{n}\right)\left(V_{E, n}-V_{U, n}\right)+\pi_{n}\left(V_{X, n}-V_{U, n}\right)+\gamma_{n}\left(\bar{V}_{U, n}-V_{U, n}\right) \\
= & r V_{U, n} .
\end{aligned}
$$

There is once more a contradiction. So, $V_{T, n}>V_{U, n}$.

To show that $V_{E, n}>V_{T, n}>V_{U, n}>V_{X, n}$, we still have to prove the first inequality. This will be done in Appendix C.

\section{Precise specification of various equations}

The steady-state relationship defining the employment level $E_{n}$ is:

$$
\begin{aligned}
& E_{n}=\mathcal{E}\left(\theta_{n}, \mathbb{S}_{n}\right) \equiv L_{n}\left[[ c _ { T , n } s _ { T , n } \alpha ( \theta _ { n } ) + \lambda _ { n } ] \left(c_{n} s_{U, n} \alpha\left(\theta_{n}\right)\left[c_{n} s_{X, n} \alpha\left(\theta_{n}\right)+\gamma_{n}\right]\right.\right. \\
& \left.\left.+\pi_{n} c_{n} s_{X, n} \alpha\left(\theta_{n}\right)\right)+\gamma_{n} c_{T, n} s_{T, n} \alpha\left(\theta_{n}\right)\left[\pi_{n}+c_{n} s_{X, n} \alpha\left(\theta_{n}\right)+\gamma_{n}\right]\right] \Delta_{0, n}^{-1},
\end{aligned}
$$

where,

$$
\begin{aligned}
& \Delta_{0, n} \equiv\left[c_{T, n} s_{T, n} \alpha\left(\theta_{n}\right)+\lambda_{n}\right]\left(\left[c_{n} s_{U, n} \alpha\left(\theta_{n}\right)+\phi_{n}\right]\left[c_{n} s_{X, n} \alpha\left(\theta_{n}\right)+\gamma_{n}\right]\right. \\
& \left.+\pi_{n}\left[c_{n} s_{X, n} \alpha\left(\theta_{n}\right)+\phi_{n}\right]\right)+\gamma_{n}\left[c_{T, n} s_{T, n} \alpha\left(\theta_{n}\right)+\phi_{n}\right]\left[\pi_{n}+c_{n} s_{X, n} \alpha\left(\theta_{n}\right)+\gamma_{n}\right] .
\end{aligned}
$$

Let

$$
\begin{aligned}
\Delta_{1, n} & \equiv\left(r+c_{n} s_{X, n} \alpha\left(\theta_{n}\right)+\gamma_{n}\right)\left[\left[r+c_{n} s_{U, n} \alpha\left(\theta_{n}\right)+\phi_{n}\right]\left[r+c_{T, n} s_{T, n} \alpha\left(\theta_{n}\right)+\lambda_{n}\right]\right. \\
& \left.+\gamma_{n}\left[r+c_{T, n} s_{T, n} \alpha\left(\theta_{n}\right)+\phi_{n}\right]\right]+\pi_{n}\left[\left[r+c_{T, n} s_{T, n} \alpha\left(\theta_{n}\right)+\lambda_{n}\right]\left[r+c_{n} s_{X, n} \alpha\left(\theta_{n}\right)+\phi_{n}\right]\right. \\
& \left.+\gamma_{n}\left[r+c_{T, n} s_{T, n} \alpha\left(\theta_{n}\right)+\phi_{n}\right]\right], \\
\Delta_{2, n} & \equiv r+\pi_{n}+c_{n} s_{X, n} \alpha\left(\theta_{n}\right)+\gamma_{n}, \\
\Delta_{3, n} & \equiv r+c_{T, n} s_{T, n} \alpha\left(\theta_{n}\right)+\lambda_{n}+\gamma_{n} .
\end{aligned}
$$


Let $\delta_{E T, n} \equiv w_{n}-v_{T, n}>0$ and $\delta_{\iota \iota^{\prime}, n} \equiv v_{\iota, n}-v_{\iota^{\prime}, n}, \iota, \iota^{\prime} \in\{U, X, T\}, \iota \neq \iota^{\prime}$. The following differences can be derived from Equations (4), (24), (26) and (25):

$$
\begin{aligned}
& V_{E, n}-V_{U, n}=\left[( r + c _ { T , n } s _ { T , n } \alpha ( \theta _ { n } ) + \lambda _ { n } ) \left[\left(r+c_{n} s_{X, n} \alpha\left(\theta_{n}\right)+\gamma_{n}\right)\left(w_{n}-v_{U, n}\right)\right.\right. \\
& \left.\left.\left.+\pi_{n}\left(w_{n}-v_{X, n}\right)\right]+\gamma_{n}\left(r+\pi_{n}+c_{n} s_{X, n} \alpha\left(\theta_{n}\right)+\gamma_{n}\right) w_{n}-v_{T, n}\right)\right] \Delta_{1, n}^{-1}, \\
& V_{U, n}-V_{X, n}=\left[\delta_{U X, n}+c_{n}\left(s_{U, n}-s_{X, n}\right) \alpha\left(\theta_{n}\right)\left(V_{E, n}-V_{U, n}\right)\right] \Delta_{2, n}^{-1}, \\
& V_{T, n}-V_{U, n}=\left[\left(r+c_{n} s_{X, n} \alpha\left(\theta_{n}\right)+\gamma_{n}\right)\left(\delta_{T U, n}+\left(c_{T, n} s_{T, n}-c_{n} s_{U, n}\right) \alpha\left(\theta_{n}\right)\right)\left(V_{E, n}-V_{U, n}\right)\right) \\
& \left.\left.+\pi_{n}\left(\delta_{T X, n}+\left(c_{T, n} s_{T, n}-c_{n} s_{X, n}\right) \alpha\left(\theta_{n}\right)\right)\left(V_{E, n}-V_{U, n}\right)\right)\right]\left[\Delta_{2, n} \Delta_{3, n}\right]^{-1}, \\
& V_{E, n}-V_{T, n}=\left[\delta_{E T, n}+\left(\lambda_{n}-\phi_{n}\right)\left(V_{T, n}-V_{U, n}\right)\right] \Delta_{4, n}^{-1} .
\end{aligned}
$$

So, if $\phi_{n}<\lambda_{n}$, one has $V_{E, n}>V_{T, n}$.

Search-effort levels verify the following (sufficient) conditions:

$$
\begin{aligned}
d^{\prime}\left(s_{U, n}\right) & =c_{n} \alpha\left(\theta_{n}\right)\left(V_{E, n}-V_{U, n}\right) \\
d^{\prime}\left(s_{X, n}\right) & =c_{n} \alpha\left(\theta_{n}\right)\left(V_{E, n}-V_{X, n}\right) \\
d^{\prime}\left(s_{T, n}\right) & =c_{T, n} \alpha\left(\theta_{n}\right)\left(V_{E, n}-V_{T, n}\right) .
\end{aligned}
$$

Under free-entry, the Nash bargain over wages leads to:

$$
V_{E, n}-V_{U, n}=\mathcal{V}\left(\theta_{n}\right) \equiv \frac{\beta_{n}}{1-\beta_{n}} \frac{k_{n}}{q\left(\theta_{n}\right)} \frac{1}{1+\tau_{n}}, \frac{\partial \mathcal{V}}{\partial \theta_{n}}>0
$$

Equation (4) can be used to replace $V_{E, n}-V_{U, n}$ by $\left(w_{n}-r V_{U, n}\right) /\left(r+\phi_{n}\right)$. So,

$$
w_{n}=r V_{U, n}+\left(r+\phi_{n}\right) \mathcal{V}\left(\theta_{n}\right) \text {. }
$$

Finally, one has to replace $r V_{U, n}$ in the previous equality. This task is more complex because the number of possible positions on the labor market is larger than in Section . It leads to the following explicit function for the wage:

$$
w_{n}=W S\left(\theta_{n}, \mathbb{S}_{n}\right) \equiv \frac{\sum_{\iota} \Omega_{\iota, n}\left(z_{n}-d\left(s_{\iota, n}\right)+c_{\iota, n} s_{\iota, n} \alpha\left(\theta_{n}\right) \mathcal{V}\left(\theta_{n}\right)\right)+\left(r+\phi_{n}\right) \mathcal{V}\left(\theta_{n}\right)}{1-\sum_{\iota} \Omega_{\iota, n} \rho_{\iota, n}},
$$

with $\iota \in\{U, X, T\}$ and

$$
\begin{aligned}
\Omega_{U, n} & \equiv\left[r+c_{T, n} s_{T, n} \alpha\left(\theta_{n}\right)+\lambda_{n}\right]\left[r+\gamma_{n}+c_{n} s_{X, n} \alpha\left(\theta_{n}\right)\right] / \Delta_{5, n} \\
\Omega_{T, n} & \equiv \gamma_{n}\left[r+\gamma_{n}+c_{n} s_{X, n} \alpha\left(\theta_{n}\right)+\pi_{n}\right] / \Delta_{5, n} \\
\Omega_{X, n} & \equiv \pi_{n}\left[r+c_{T, n} s_{T, n} \alpha\left(\theta_{n}\right)+\lambda_{n}\right] / \Delta_{5, n} \\
\Delta_{5, n} & \equiv\left[r+c_{T, n} s_{T, n} \alpha\left(\theta_{n}\right)+\lambda_{n}+\gamma_{n}\right]\left[r+\gamma_{n}+c_{n} s_{X, n} \alpha\left(\theta_{n}\right)+\pi_{n}\right]
\end{aligned}
$$


and $\Omega_{U, n}+\Omega_{T, n}+\Omega_{X, n}=1$. As in the model of Section, it can be shown that this curve is not affected by marginal changes in search effort levels.

In a symmetric equilibrium, Expression (50) can be substituted for $V_{E, n}-V_{U, n}$ in the first-order conditions (47), (48) and (49) in which $V_{U, n}-V_{X, n}$ has first been replaced by (44) and $V_{T, n}-V_{U, n}$ by (45). After some manipulation, this leads for each $n$ to:

$$
\begin{aligned}
& \Sigma_{U}\left(\theta_{n}, s_{U, n}\right) \equiv d^{\prime}\left(s_{U, n}\right)-c_{n} \alpha\left(\theta_{n}\right) \mathcal{V}\left(\theta_{n}\right)=0, \\
& \Sigma_{X}\left(\theta_{n}, s_{U, n}, s_{X, n}\right)=0
\end{aligned}
$$

with $\quad \Sigma_{X} \equiv \Delta_{2, n} d^{\prime}\left(s_{X, n}\right)-c_{n} \alpha\left(\theta_{n}\right)\left[\delta_{U X, n}+\left(\Delta_{2, n}+c_{n}\left[s_{U, n}-s_{X, n}\right] \alpha\left(\theta_{n}\right)\right) \mathcal{V}\left(\theta_{n}\right)\right]$,

$$
\Sigma_{T}\left(\theta_{n}, s_{U, n}, s_{X, n}, s_{T, n}\right)=0
$$

with $\quad \Sigma_{T} \equiv \Delta_{2, n} \Delta_{3, n} d^{\prime}\left(s_{T, n}\right)-c_{T, n} \alpha\left(\theta_{n}\right)\left[\left(\Delta_{2, n} \Delta_{3, n}-\left[r+c_{n} s_{X, n} \alpha\left(\theta_{n}\right)+\gamma_{n}\right]\right.\right.$

$$
\begin{aligned}
& \left.\left[c_{T, n} s_{T, n}-c_{n} s_{U, n}\right] \alpha\left(\theta_{n}\right)-\pi_{n}\left[c_{T, n} s_{T, n}-c_{n} s_{X, n}\right] \alpha\left(\theta_{n}\right)\right) \mathcal{V}\left(\theta_{n}\right) \\
& \left.-\left(r+c_{n} s_{X, n} \alpha\left(\theta_{n}\right)+\gamma_{n}\right) \delta_{T U, n}-\pi_{n} \delta_{T X, n}\right] .
\end{aligned}
$$

Totally differentiating equations (53), (54) and (55), it can be checked that $\frac{\partial \Sigma_{\iota}}{\partial s_{\iota^{\prime}}}=$ $0 \forall \iota, \iota^{\prime} \in\{\{T, n\},\{X, n\},\{U, n\}\}, \iota \neq \iota^{\prime}$. Moreover, the levels of search effort of type- $n$ workers increase with tightness $\theta_{n}$ and decrease with the tax rate $\tau_{n}$.

Expression (48) implies that $s_{X, n}$ increases with the gain $V_{E, n}-V_{X, n}=V_{E, n}-$ $V_{U, n}+V_{U, n}-V_{X, n}=\mathcal{V}\left(\theta_{n}\right)+V_{U, n}-V_{X, n}$. As $V_{T, n}>V_{U, n}>V_{X, n}$, those in state $X_{n}$ gain more from the ALMP than those in $U_{n}$. Therefore, Van der Linden (2005) shows that $V_{U, n}-V_{X, n}$ shrinks with $\gamma_{n}$ and so does $s_{X, n}$ (conditional on $\theta_{n}$ ). From (49), $s_{T, n}$ increases with the gain $V_{E, n}-V_{T, n}=\mathcal{V}\left(\theta_{n}\right)-\left(V_{T, n}-V_{U, n}\right)$. Van der Linden (2005) shows that $V_{T, n}-V_{U, n}$ shrinks with $\gamma_{n}$ (conditional on $\theta_{n}$ ). And so, the direct effect of $\gamma_{n}$ on $s_{T, n}$ is positive.

\section{Comparative static analysis}

The equilibrium effect of a marginal change in $\gamma_{l}$ can be measured by differentiating the following system where $\left(\theta_{l}, \theta_{h}\right)$ are the endogenous variables and $\gamma_{l}$ is the parameter of interest here:

$$
\begin{aligned}
& V S_{l}\left(\theta_{l}, \theta_{h} \mid \gamma_{l}\right)-W S_{l}\left(\theta_{l} \mid \gamma_{l}\right)=0 \\
& V S_{h}\left(\theta_{l}, \theta_{h} \mid \gamma_{l}\right)-W S_{h}\left(\theta_{h}\right)=0
\end{aligned}
$$

In these equations, $V S_{n}\left(\theta_{n}, \theta_{m} \mid \gamma_{n}\right)$ is defined by (9) where

$$
p_{n}=\frac{\partial F\left(\mathcal{E}\left(\theta_{l}, \mathbb{S}_{l}\right) y_{l}, \mathcal{E}\left(\theta_{h}, \mathbb{S}_{h}\right) y_{h}\right)}{\partial E_{n} y_{n}}
$$


$\mathbb{S}_{n}$ is a function of $\theta_{n}$ and, if $n=l$, of $\gamma_{l}$ (see (53) to (55)). ${ }^{34}$ The function $\mathcal{E}\left(\theta_{l}, \mathbb{S}_{l}\right)$ is influenced by $\gamma_{l}$ (see (40)). In System (56), the $W S_{n}$ functions are defined by (52). ${ }^{35}$ As can be seen from this definition, $\gamma_{l}$ influences $W S_{l}$ conditional on $\theta_{l}$.

Differentiating with respect to $\theta_{l}, \theta_{h}$ and $\gamma_{l}$ leads to:

$$
\frac{d \theta_{l}}{d \gamma_{l}}=-\frac{\operatorname{det}\left[\begin{array}{cl}
\frac{\partial V S_{l}}{\partial \gamma_{l}}-\frac{\partial W S_{l}}{\partial \gamma_{l}} & \frac{\partial V S_{l}}{\partial \theta_{h}} \\
\frac{\partial V S_{h}}{\partial \gamma_{l}} & \left.\frac{\partial V S_{h}}{\partial \theta_{h}}-\frac{\partial W S_{h}}{\partial \theta_{h}}\right]
\end{array}\right]}{\operatorname{det}\left[\begin{array}{cl}
\frac{\partial V S_{l}}{\partial \theta_{l}}-\frac{\partial W S_{l}}{\partial \theta_{l}} & \frac{\partial V S_{l}}{\partial \theta_{h}} \\
\frac{\partial V S_{h}}{\partial \theta_{l}} & \frac{\partial V S_{h}}{\partial \theta_{h}}-\frac{\partial W S_{h}}{\partial \theta_{h}}
\end{array}\right]}<0 .
$$

Consider first the matrix at the numerator. We know that $\frac{\partial W S_{l}}{\partial \gamma_{l}}>0$. Moreover,

$$
\frac{\partial V S_{l}}{\partial \gamma_{l}}=\frac{y_{l}}{1+\tau_{1, l}} \frac{\partial p_{l}}{\partial\left(E_{l} y_{l}\right)}\left[\frac{\partial \mathcal{E}\left(\theta_{l}, \mathbb{S}_{l}\right)}{\partial \gamma_{l}}+\sum_{\iota \in U, X, T} \frac{\partial \mathcal{E}\left(\theta_{l}, \mathbb{S}_{l}\right)}{\partial s_{\iota, l}} \frac{\partial s_{\iota, l}}{\partial \gamma_{l}}\right]
$$

Looking at equation (40) we have that $\frac{\partial E_{l}}{\partial \gamma_{l}}>0$ if $c_{T, l} s_{T, l}$ is "sufficiently larger" than $c_{l} s_{U, l}$ and $c_{l} s_{X, l} \cdot{ }^{36}$ However, the direct effects of $\gamma_{l}$ on $s_{U, l}$ is nil, on $s_{X, l}$ is negative and on $s_{T, l}$ is positive (see the end of Appendix C). So, in (58), the sign of the sum between brackets is ambiguous. Therefore, it can be checked that the sign of $d \theta_{l} / d \gamma_{l}$ is in general ambiguous, too.

Let us however assume that the expression between brackets in (58) is nonnegative. Then, we have $\frac{\partial V S_{l}}{\partial \gamma_{l}} \leq 0$ since $\frac{\partial p_{l}}{\partial E_{l}}<0$ and so $\frac{\partial V S_{l}}{\partial \gamma_{l}}-\frac{\partial W S_{l}}{\partial \gamma_{l}}<0$. Moreover then, $\frac{\partial V S_{h}}{\partial \gamma_{l}} 37$ is nonnegative since $\frac{\partial p_{h}}{\partial E_{l}}>0$. It can easily be checked that $\frac{\partial V S_{l}}{\partial \theta_{h}}>0$ and

\footnotetext{
${ }^{34}$ Looking at these equations, it turns out that conditional on tightness, $s_{U, n}$ is not affected by $\gamma_{n}$.

${ }^{35}$ In which again $\mathbb{S}_{n}$ is a function of $\theta_{n}$ but this does not matter since marginal changes in search effort do not shift the wage-setting curve.

36

$$
\begin{aligned}
& \frac{\partial E_{n}}{\partial \gamma_{n}}=\frac{\phi_{n}\left(c_{T, n} s_{T, n} \alpha\left(\theta_{n}\right)+\lambda_{n}\right)}{\Delta_{0, n}^{2}}\left[\pi_{n}\left(c_{T, n} s_{T, n} \alpha\left(\theta_{n}\right)+\lambda_{n}+\gamma_{n}\right) c_{n}\left(s_{U, n}-s_{X, n}\right) \alpha\left(\theta_{n}\right)\right. \\
& +\left(\pi_{n}+c_{n} s_{X, n} \alpha\left(\theta_{n}\right)+\gamma_{n}\right)\left(\left(c_{n} s_{X, n} \alpha\left(\theta_{n}\right)+\gamma_{n}\right)\left(c_{T, n} s_{T, n}-c_{n} s_{U, n}\right) \alpha\left(\theta_{n}\right)\right. \\
& \left.\left.\left.+\pi_{n}\left(c_{T, n} s_{T, n}-c_{n} s_{X, n}\right) \alpha\left(\theta_{n}\right)\right)\right)\right] \\
& \geq 0 \quad \text { if } c_{T, n} s_{T, n} \text { is sufficiently larger than } c_{n} s_{U, n} \text { and } c_{n} s_{X, n} \\
& <0 \quad \text { if } c_{T, n} s_{T, n}<c_{n} s_{U, n} \text { and } c_{T, n} s_{T, n}<c_{n} s_{X, n}
\end{aligned}
$$$$
37 \frac{\partial V S_{h}}{\partial \gamma_{l}}=\frac{y_{h}}{1+\tau_{1, h}} \frac{\partial p_{h}}{\partial E_{l}}\left[\frac{\partial \mathcal{E}\left(\theta_{l}, \mathbb{S}_{l}\right)}{\partial \gamma_{l}}+\sum_{\iota \in U, X, T} \frac{\partial \mathcal{E}\left(\theta_{l}, \mathbb{S}_{l}\right)}{\partial s_{\iota, l}} \frac{\partial s_{\iota, l}}{\gamma_{l}}\right] .
$$ 
$\frac{\partial V S_{h}}{\partial \theta_{h}}-\frac{\partial W S_{h}}{\partial \theta_{h}}<0$. Since, using again Euler's formula, we can prove that

$$
\frac{\partial V S_{l}}{\partial \gamma_{l}} \frac{\partial V S_{h}}{\partial \theta_{h}}>\frac{\partial V S_{h}}{\partial \gamma_{l}} \frac{\partial V S_{l}}{\partial \theta_{h}}
$$

the numerator in (57) is then positive, too. So does the denominator. Therefore, we conclude that $\frac{d \theta_{l}}{d \gamma_{l}}$ is negative if the direct effect of $\gamma_{l}$ on $E_{l}$ (i.e., the expression between brackets in (58)) is nonnegative.

To check the sign of $\frac{d \theta_{h}}{d \gamma_{l}}$ we follow the same procedure. The numerator is equal to:

$$
\underbrace{\left(\frac{\partial V S_{l}}{\partial \theta_{l}}-\frac{\partial W S_{l}}{\partial \theta_{l}}\right)}_{-} \underbrace{\frac{\partial V S_{h}}{\partial \gamma_{l}}}_{+ \text {or } 0}-\underbrace{\frac{\partial V S_{h}}{\partial \theta_{l}}}_{+} \underbrace{\left(\frac{\partial V S_{l}}{\partial \gamma_{l}}-\frac{\partial W S_{l}}{\partial \gamma_{l}}\right)}_{-} .
$$

We are not able to sign the determinant at the numerator. So, the marginal effect of $\gamma_{l}$ on $\theta_{h}$ is ambiguous. 
Table 1.

Calibration: Parameters and levels of endogenous variables in steady state

\begin{tabular}{ccc}
\hline Parameters & $l$ & $h$ \\
\hline$\phi$ & 0.009 & 0.006 \\
$p y($ Euro/month $)$ & 3300 & 4200 \\
$k$ & 18211 & 41442 \\
$\rho_{U}=b_{U} / w$ & 0.55 & 0.55 \\
$\rho_{X}=b_{X} / w$ & 0.43 & 0.40 \\
$\tau$ & 1.00 & 1.17 \\
$\gamma$ & 0.006 & 0.02 \\
$\lambda$ & 0.1 & 0.1 \\
$\pi$ & 0.083 & 0.083 \\
$\psi$ & 7.4 & 7.4 \\
$\xi$ & 1.142 & 1.139 \\
$\beta$ & 0.56 & 0.50 \\
$c$ & 0.17 & 0.31 \\
$c_{T}$ & 0.19 & 0.34 \\
\hline Endogenous var. & & \\
\hline$u$ & 0.056 & 0.031 \\
$t$ & 0.139 & 0.027 \\
$e$ & 0.008 & 0.006 \\
$p$ & 0.61 & 0.75 \\
$s_{U}\left(c s_{U} \alpha(\theta)\right)$ & 0.54 & 0.72 \\
$s_{X}\left(c s_{X} \alpha(\theta)\right)$ & $0.20(0.04)$ & $0.49(0.10)$ \\
$s_{T}\left(c_{T} s_{T} \alpha(\theta)\right)$ & $0.26(0.06)$ & $0.55(0.12)$ \\
$\theta$ & 2.22 & 0.83 \\
$V /\left(U+X_{X}+T\right)$ & 0.09 & 0.14 \\
\hline$($ Euro $/$ month $)$ & 1229 & 1512 \\
\hline & &
\end{tabular}




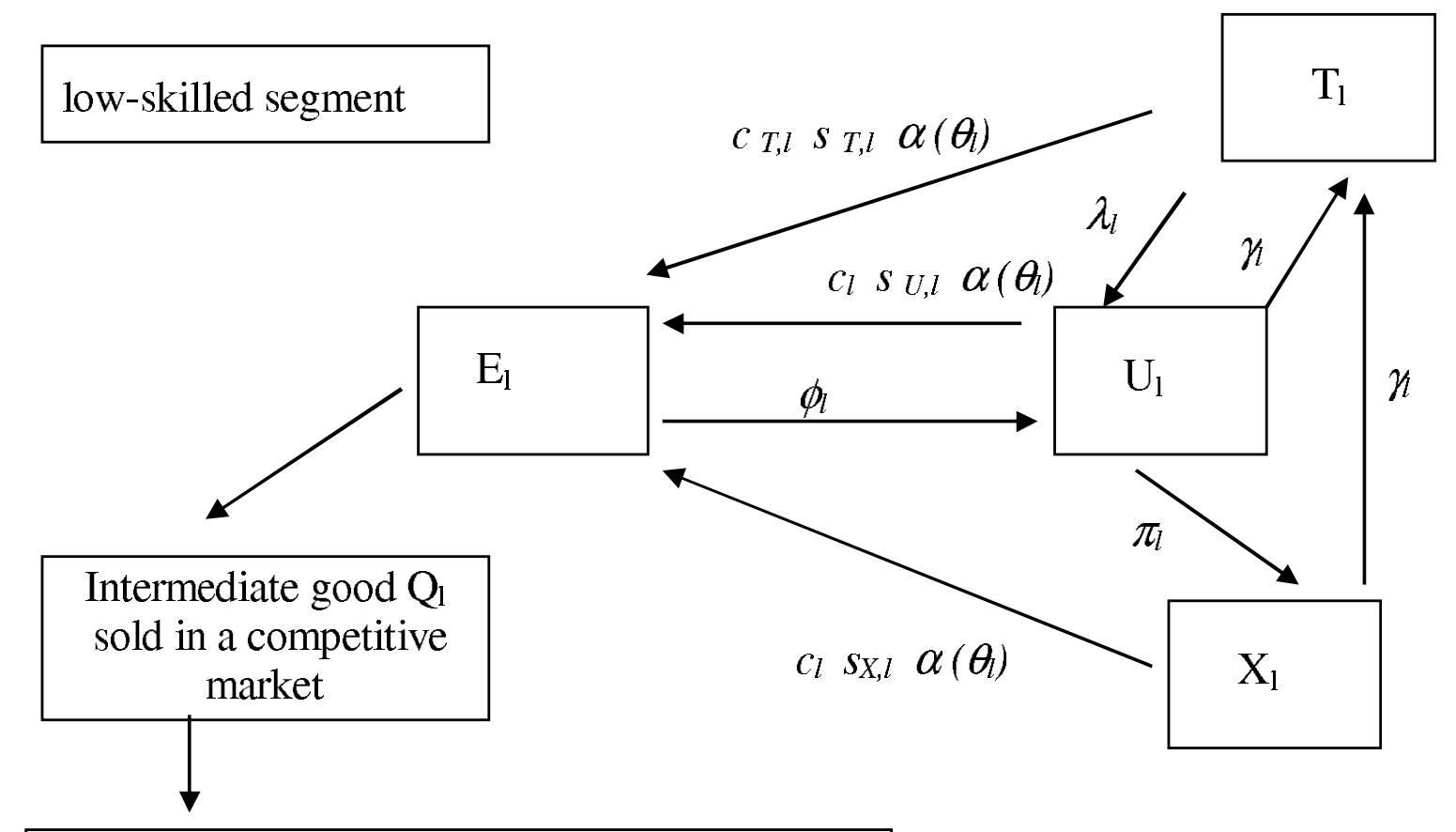

Final good representative firm $Y=F\left(Q_{\mathrm{l}}, Q_{h}\right)$

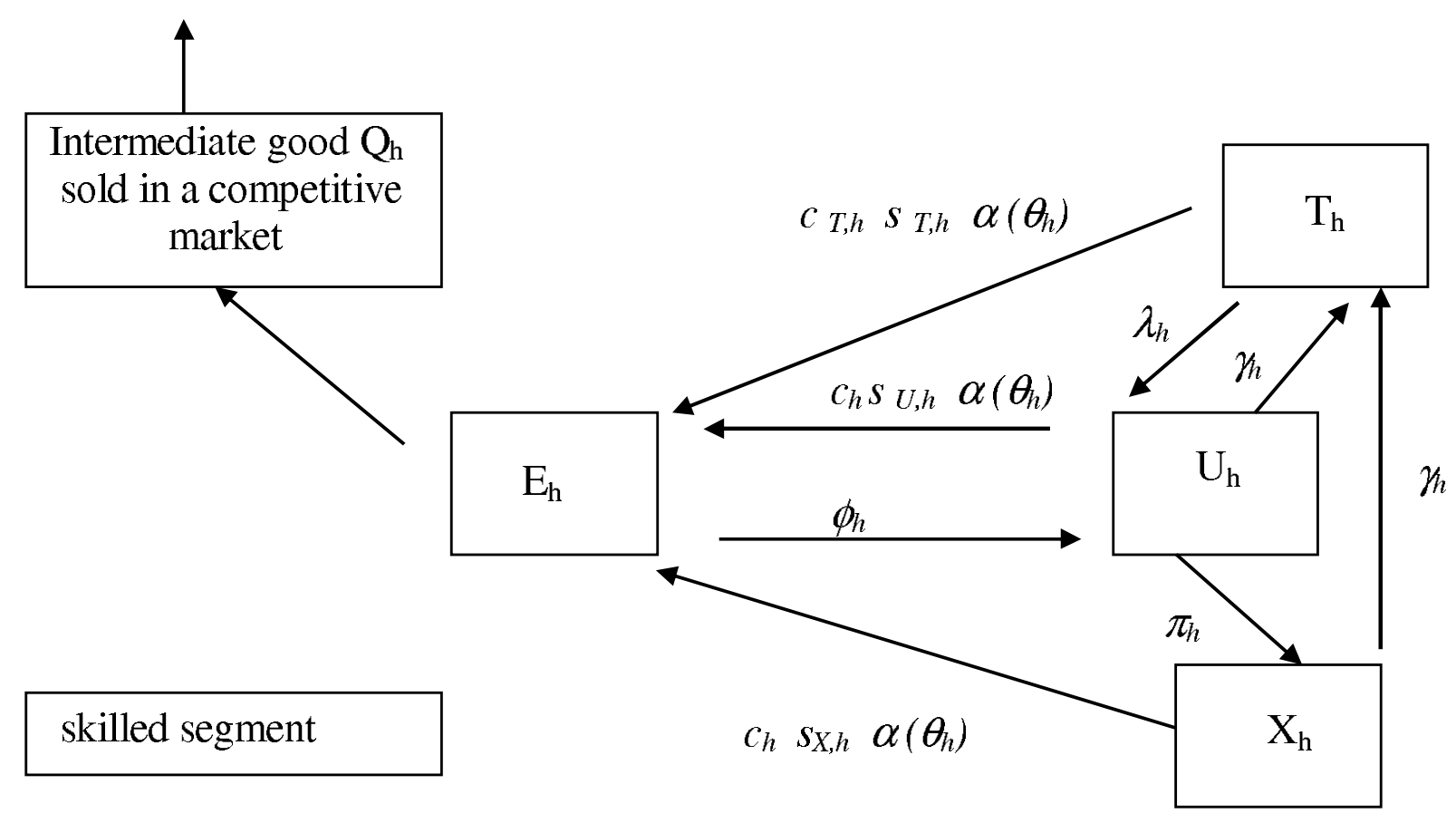

Figure 2: Labor market flows. 

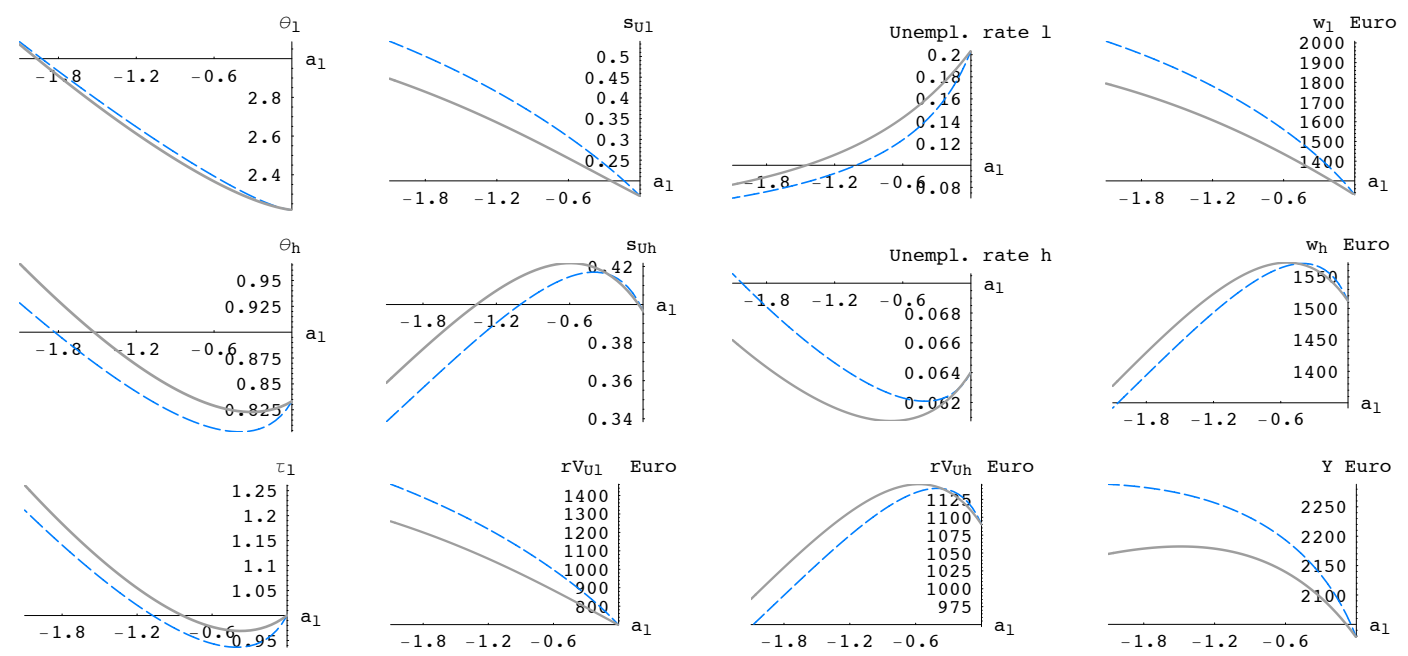

Figure 3: Various indicators as a function of $a_{l}$ in 1000 Euro. Interrupted (respectively, thick) lines: When the marginal values of labor are fixed (resp., when they vary). The budget constraint (28) is binding. 